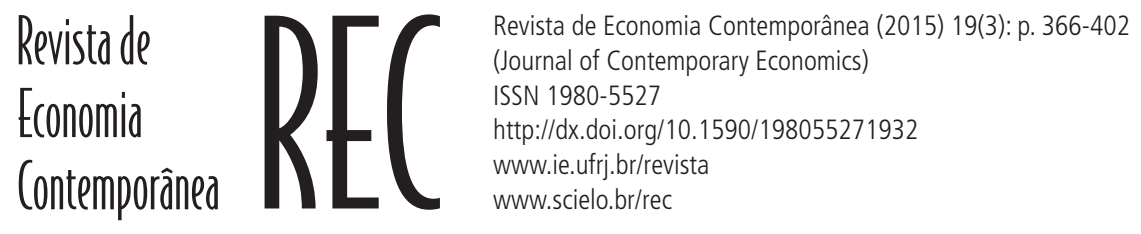

\title{
A QUESTÃO DA MOBILIDADE URBANA NAS METRÓPOLES BRASILEIRAS
}

\author{
Valéria Pero $^{a}$ \\ Victor Stefanellib \\ aProfessora do Instituto de Economia da Universidade Federal do Rio de Janeiro (UFRJ). \\ ${ }^{\mathrm{b}}$ Graduado pelo Instituto de Economia da UFRJ. \\ Artigo recebido em 09/11/2015 e aprovado 15/12/2015.
}

RESUMO: O tempo de deslocamento de casa ao trabalho tem se elevado substancialmente nas regiões metropolitanas brasileiras durante a última década. Esse fenômeno tem implicações fortes sobre o bem-estar dos indivíduos, porém as consequências desse problema não se distribuem uniformemente entre a população. $O$ presente trabalho visa contribuir para o debate sobre a questão da mobilidade urbana nas metrópoles brasileiras analisando a evolução do tempo de deslocamento entre 1992 e 2013 e suas diferenças de acordo com características do trabalhador, como sexo, cor e renda per capita, e do posto de trabalho. Verifica-se que o aumento do tempo médio de deslocamento ocorreu a partir de 2003, caracterizando uma questão particularmente importante para as metrópoles brasileiras no terceiro milênio. Os trabalhadores com maiores tempos médios de deslocamento residem nas regiões metropolitanas do Rio de Janeiro e de São Paulo. Entretanto, as maiores taxas de crescimento ocorreram nas metrópoles do Pará, Salvador e Recife, sugerindo a necessidade de melhor direcionamento e planejamento de políticas públicas na mobilidade urbana. Considerando as diferenças socioeconômicas, destaca-se que os mais pobres e os mais ricos (extremos da distribuição de renda) tendem a apresentar tempos de deslocamento menores do que os trabalhadores de famílias de renda média. Esse padrão se mantém ao longo do tempo, com aumento do tempo médio de deslocamento entre os mais pobres, mostrando uma face da desigualdade. Porém, o maior aumento ocorreu entre os mais ricos, colocando a questão da mobilidade urbana para além dos problemas de exclusão social.

PALAVRAS-CHAVE: mobilidade urbana; tempo de deslocamento; região metropolitana; mercado de trabalho.

CLASSIFICAÇÃO JEL: J61; R41. 


\title{
THE EVOLUTION OF COMMUTING TIME IN METROPOLITAN BRAZIL BETWEEN 1992 AND 2013
}

\begin{abstract}
The commuting time has risen substantially at metropolitan areas in Brazil over the last decade. This phenomenon has strong implications on the well-being of individuals, on the labor supply patterns and on regional urban development. However, the consequences of this problem are unevenly distributed among the population. This paper aims to contribute to the debate of urban mobility issue in Brazilian cities by analyzing the commuting time evolution between 1992 and 2013 and their differences according to the workers own characteristics, such as gender, race, income, and job. The average commuting time raised since 2003, featuring a particularly important issue for Brazilian metropolises in the second millennium. Workers with higher average commuting times reside in the metropolitan areas of Rio de Janeiro and São Paulo. However, the highest growth rates occurred in the metropolitan areas of Pará, Salvador and Recife, suggesting the need for better-targeted and planned urban mobility public policies. Considering the socioeconomic differences, the poorest and the richest (extremes of the income distribution) tend to have lower commuting times than the general population. This pattern is maintained over time, with higher average commuting time between the poorest, showing a face of inequality. However, the travel time of the richest grew more than among the poorest, which raises the question of urban mobility beyond the problems of social exclusion.
\end{abstract}

KEYWORDS: urban mobility; commuting time; labor market; metropolitan region. 


\section{INTRODUÇÃO}

O tempo de deslocamento de casa ao trabalho é fator crucial na qualidade de vida, na medida em que afeta a jornada cotidiana do trabalhador. Assim, a mobilidade urbana exerce uma influência indireta, mas significativa, sobre o bem-estar. Além disso, é um tema central na discussão sobre desenvolvimento regional urbano, principalmente em regiões metropolitanas.

O Brasil é um país em estado avançado de transição urbana (Ojima et al., 2013, p. 2), o que se reflete na recente expansão da frota de veículos, facilitada pela maior oferta de crédito e melhorias na distribuição da renda. Segundo Martine et al. (2012, p. 178), a frota de veículos brasileiros dobrou entre 2000 e 2012, passando de 19,9 milhões para 40 milhões, o que provocou um aumento da relação entre habitantes por carro de 9:1 em 2000 para 5:1 em 2012. O resultado dessa expansão são os frequentes congestionamentos, agravados pela ausência de investimentos significativos em transporte coletivo de massa, um dos motivos por trás das manifestações de junho de 2013.

O tempo de deslocamento de casa ao trabalho depende da distância, do modal a ser utilizado e do congestionamento, possuindo uma relação muito sensível com a dinâmica de oportunidades de emprego e de moradia das diversas metrópoles na sua conformação. Já os custos (monetários ou não) dependem também da qualidade do transporte público. Assim, compreender melhor a situação da mobilidade urbana nas metrópoles é fundamental para a formulação de políticas públicas sobre as melhores alternativas em termos de mobilidade urbana, ou seja, as que reduzam o tempo de deslocamento e/ou seus custos, dadas as configurações espaciais e socioeconômicas de cada região.

A lógica da solução para o problema de locomoção individual dentro das cidades apresenta características que contradizem a noção clássica smithiana de que a busca pelos interesses individuais levaria, em geral, à melhoria do bem comum. O indivíduo, perseguindo seu interesse particular, soluciona o problema da locomoção optando pelo transporte motorizado privado, comumente o carro. Embora resolva seu problema particular, agrava a situação coletiva: ao adicionar mais um carro ao fluxo de automóveis na cidade, eleva o custo marginal para todo o restante da sociedade, pois haverá uma diminuição na velocidade média e um aumento no congestionamento. Assim, a opção pelo transporte individual pode fazer sentido do ponto de vista privado, mas é no mínimo questionável do ponto de vista coletivo.

Tais congestionamentos geram externalidades negativas e custos sociais. Para Cintra (2008 apud Moraes, 2013, p. 43), a principal perda é, na verdade, um custo de oportunidade, ou seja, "o tempo em que o trabalhador fica retido dentro de um veículo representa o desperdício de sua capacidade produtiva, alijada parcialmente do processo de produção pela sua permanência muito além do ideal dentro de um veículo, 
por força dos congestionamentos". Outro tipo de perda seria o relativo à produtividade, uma vez que estar preso em um congestionamento gera um desconforto ao trabalhador, o que pode acarretar redução da produtividade na ordem de $20 \%$ (Branco, 1999, apud Moraes, 2013, p. 43). Porém, existem diversos custos associados à mobilidade urbana: tempo de viagem, saúde, estacionamento, valor dos terrenos usados como vias, manutenção dos serviços de tráfego, poluição do ar e sonora, gasto adicional com combustível, entre outros.

Monetizar as perdas com o congestionamento é uma forma de abordar vários desses custos e externalidades conjuntamente. Young et al. (2013, p. 12) usam dados sobre o tempo de deslocamento e a renda do trabalho do Censo Demográfico de 2010 para estimar tais custos no Rio de Janeiro, que variaram entre $\mathrm{R} \$ 6,7$ e R \$ 13,5 bilhões apenas na região metropolitana, o que corresponderia a 1,9\% e 3,8\% do Produto Interno Bruto (PIB) estadual do mesmo ano, respectivamente. Em nível nacional, o Instituto Akatu (2013) estima que se as pessoas residentes em regiões metropolitanas (RMs) fossem capazes de reduzir seu tempo de deslocamento de casa ao trabalho para 30 minutos, o PIB aumentaria em R 200 bilhões (mais de 4\% do PIB de 2013).

Assim, compreender a dinâmica socioeconômica da mobilidade urbana no Brasil é extremamente relevante, uma vez que: (1) envolve questões de interesse, como bemestar, produtividade, poluição etc.; e (2) as soluções para essas questões vão além das técnicas relativas à engenharia de transportes, envolvendo também políticas públicas de transporte urbano e de desenvolvimento local.

Esse artigo visa contribuir com a literatura sobre o tema a partir da análise da evolução do tempo de deslocamento de casa ao trabalho nas nove principais regiões metropolitanas brasileiras e no Distrito Federal entre 1992 e 2013. A análise ressalta ainda como o tempo gasto em deslocamento casa-trabalho varia de acordo com características pessoais, como gênero e cor, e características socioeconômicas, como renda e posto de trabalho. Com isso, pretende-se identificar as diferenças nas tendências e padrões da mobilidade urbana entre as regiões metropolitanas brasileiras, com base nos dados da Pesquisa Nacional por Amostra de Domicílios (PNAD), gerados pelo Instituto Brasileiro de Geografia e Estatística (IBGE).

Verifica-se um aumento do tempo médio de deslocamento de casa ao trabalho nas regiões metropolitanas brasileiras entre 1992 e 2013, com exceção de Fortaleza. Esse aumento, no entanto, não foi contínuo, tendo ocorrido a partir de 2003, caracterizando uma questão particularmente importante para as metrópoles no terceiro milênio. Os trabalhadores com maiores tempos médios de deslocamento residem nas regiões metropolitanas do Rio de Janeiro e de São Paulo. Porém, as maiores taxas de crescimento ocorreram nas metrópoles do Pará, Salvador e Recife, sugerindo melhor direcionamento e planejamento de políticas públicas na mobilidade urbana. 
Considerando as diferenças socioeconômicas, o tempo médio de deslocamento é maior entre os homens, mas como cresceu mais entre as mulheres, em 2013 quase não existe diferença. Já o tempo maior entre os negros do que entre os brancos permanece ao longo do período. Os trabalhadores formais com auxílio-transporte são os que registram os maiores tempos de deslocamento de casa ao trabalho, levantando a hipótese de condições mais atrativas para trabalhadores residentes em localidades distantes. Por fim, os mais pobres e os mais ricos (extremos da distribuição de renda) tendem a apresentar tempos de deslocamento menores do que o restante da população. Uma explicação possível seria que os mais pobres possuem um raio de busca por empregos menor devido aos custos de transporte impeditivos; enquanto os mais ricos podem arcar com os custos de residir mais perto dos polos de emprego e de utilizar transporte individual motorizado. Porém, o tempo de deslocamento dos mais ricos cresceu mais do que entre os mais pobres, o que coloca a questão da mobilidade urbana para além dos problemas de exclusão social.

Assim sendo, esse artigo está organizado da seguinte forma: a primeira seção faz uma breve revisão da literatura internacional sobre mobilidade urbana, considerando a questão do tempo de deslocamento de casa ao trabalho nas metrópoles. Em seguida, apresenta-se o contexto brasileiro para a questão da evolução do tempo de deslocamento nas grandes metrópoles. A seção 3 descreve a base de dados, o universo e as variáveis de análise; para na próxima seção elaborar-se a análise da evolução do tempo de deslocamento de casa ao trabalho no Brasil entre 1992 e 2013, comparando as nove maiores regiões metropolitanas e o Distrito Federal. A seção 5 analisa os diferenciais observados segundo características individuais e do posto de trabalho, levantando algumas possíveis explicações para os padrões e as tendências observados entre as regiões metropolitanas brasileiras. Por fim, destacam-se os principais resultados e apontam-se questões para futuras pesquisas e discussões sobre mobilidade urbana no Brasil.

\section{UMA BREVE REVISÃO DA LITERATURA ECONÔMICA SOBRE DETERMINANTES SOCIOECONÔMICOS DO TEMPO DE DESLOCAMENTO NAS METRÓPOLES}

De forma geral, podemos conceituar mobilidade urbana como sendo um atributo relacionado aos deslocamentos realizados pelos indivíduos em suas atividades de estudo, trabalho, lazer e outras nas áreas urbanas. Sob essa ótica, fica evidente o papel central das cidades, como locus das diversas relações de troca de bens e serviços, cultura e conhecimento entre seus habitantes, o que só é viável se atendidas as condições mínimas adequadas de mobilidade para a população (Ministério das Cidades, 2006, 
apud Magagnin e Silva, 2008, p. 26). Para efeitos deste estudo, será dado enfoque apenas ao tempo de deslocamento dos trabalhadores de casa ao trabalho.

Qualquer pesquisa breve nos principais repositórios de artigos acadêmicos evidenciará uma vasta gama de trabalhos sobre transporte urbano. Porém, a grande maioria dos estudos publicados na área de mobilidade urbana centra-se na experiência de países desenvolvidos ${ }^{1}$. Como esse fenômeno está intrinsecamente associado ao tipo de experiência de urbanização dos países, verificam-se dificuldades na adaptação das teorias para os países subdesenvolvidos, que historicamente apresentaram processos de urbanização acelerado e retardatário ao mesmo tempo, como México, Brasil e Argentina (Rivière D’arc, 2014, p. 142). Assim, existem poucos estudos que analisem as variações no tempo de deslocamento, menos ainda são os que estudam esse fenômeno dentro de áreas metropolitanas e em países fora do seleto grupo dos desenvolvidos.

Embora tratem de realidades muito distintas da brasileira, ou de qualquer outro país em desenvolvimento, as discussões presentes na literatura internacional sobre o tema oferecem um ponto de partida analítico para a avaliação desse fenômeno.

Levinson e Kumar (1994) estudaram a dinâmica do tempo médio de deslocamento nos Estados Unidos e observaram que este era aproximadamente estável, o que os levou a formular a co-location hypothesis, segundo a qual os trabalhadores optariam por mudar de emprego e local de residência visando reduzir o seu tempo de deslocamento e evitar congestionamentos. Ao mesmo tempo, as empresas estariam submetidas a um tipo de dilema parecido, no qual optariam por alterar a localização de suas instalações para fugir dos congestionamentos e da elevação no custo da terra. Seguindo o raciocínio microeconômico clássico de equilíbrio entre mercados, essas escolhas diminuiriam o tempo de deslocamento dentro da região metropolitana, o que levaria a uma maior descentralização espacial.

Mesmo se tratando de um país desenvolvido, é difícil conceber a ideia de que os trabalhadores subordinariam a decisão de onde trabalhar (empresa e local) e morar ao tempo de deslocamento e ao congestionamento. A crítica de Cervero e Wu (1998, p. 1065) vai nessa direção: existiriam dificuldades em mudar de localização, uma vez que o trabalhador está inserido em um núcleo familiar, o que significa que a sua escolha afetará também o tempo de deslocamento de outros membros da família. Adicionalmente, para além dos custos de transporte extremamente altos, seria necessário supor um vasto conjunto de combinações vagas-localidade-moradia que permita ao trabalhador "reequilibrar" seu tempo de deslocamento sem modificar seu rendimento do

1 Sobre os Estados Unidos, ver McLafferty e Preston (1996); Crane (2007); Crane e Takahashi (2009); sobre o Reino Unido, ver Gibbons e Machin (2006); e sobre a Holanda, ver Van Ommeren et al. (2000). 
trabalho. Os autores, ao analisarem o mercado de terras de São Francisco, também verificaram que os altos custos da terra e dos aluguéis nas áreas próximas às concentrações de emprego impediriam que trabalhadores, em especial os de baixa renda, morassem perto do seu local de trabalho.

As críticas à co-location hypothesis não são apenas teóricas. Esse é o caso do trabalho de Levinson e Wu (2005), no qual a co-location hypothesis é rejeitada para o caso americano, devido à natureza dos dados das décadas de 1980 e 1990, que apontam para um aumento no tempo de viagem no nível metropolitano.

Estudos empíricos ${ }^{2}$ para países desenvolvidos têm mostrado que diferenças entre durações de viagem casa-trabalho entre localidades estão relacionadas às diferenças de densidade demográfica, nível de concentração de empregos nos centros, área espacial da região metropolitana, características de emprego, status socioeconômico dos trabalhadores e outras características como idade, situação do domicílio, sexo e renda, sendo as duas últimas especialmente importantes (Pereira e Schwanen, 2013, p. 8).

Dentre os estudos que focam na influência de características pessoais no tempo de deslocamento nos Estados Unidos, destacam-se os de McLafferty e Preston (1996), Crane (2007), Crane e Takahashi (2009), concluindo que as diferenças de tempo de viagem entre homens e mulheres permaneceram praticamente inalteradas durante a década de 1980 (McLafferty e Preston, 1996, p. 427), e que essa diferença aumentou, embora pouco, entre 1985 e 2005, contradizendo a "revolução silenciosa" que supostamente estaria ocorrendo entre as mulheres. Crane e Takahashi (2009, p. 330) mostram ainda como essas diferenças entre homens e mulheres (com homens tendo viagens mais demoradas) variam também de acordo com cor/raça, com alargamento da diferença (em especial entre negros e latinos), e idade, com aumento do diferencial de tempo de deslocamento conforme a idade aumenta.

Glaeser (1998, p. 150) defende que o entendimento do deslocamento casa-trabalho passa por considerar o custo de transporte e o custo habitacional simultaneamente. Um modelo teórico compatível com essa ideia seria o de Alonso-Muth ${ }^{3}$, no qual os preços de equilíbrio são maiores nas proximidades do centro da cidade, para contrabalancear os menores custos de transporte casa-trabalho (Alonso, 1961 e Muth, 1969).

Para o caso norte-americano, Glaeser (1998, p. 150) observou que o custo de vida aumenta de acordo com o tamanho da cidade. A elasticidade do log do custo de vida ${ }^{4}$

2 Para uma revisão completa desses estudos, ver Pereira e Schwanen (2013).

3 Para um detalhamento do modelo ver Alonso (1961) e Muth (1969).

4 O autor utilizou o log do índice de custo de vida apurado pela American Chamber of Commerce Research Association em seu Statistical Abstract de 1993. Essa medida de elasticidade representa o quão sensível o 
de se morar em uma área metropolitana era de 0,16 (ou de 0,11, excluindo-se a cidade de Nova Iorque), ou seja, viver em uma cidade grande custa mais do que em uma cidade pequena. O custo habitacional é parte integrante do custo de vida e, segundo os cálculos de Glaeser, a elasticidade do preço médio dos imóveis em relação ao tamanho da cidade era de 0,18 (levemente maior do que o custo de vida geral). Assim, o autor conclui que não há dúvidas quanto à relação custo habitacional e tamanho da cidade, refletindo uma predisposição dos indivíduos a pagar pelas vantagens da vida urbana, e mais ainda pelos benefícios de se morar no centro da cidade (em especial os relativos ao transporte, ideia central do modelo Alonso-Muth).

No mesmo estudo, Glaeser (1998, p. 151) apresenta a correlação entre o log da população em regiões metropolitanas dos EUA e o tempo (em minutos) de deslocamento casa-trabalho. Os resultados mostraram que, para cidades com menos de 100 mil habitantes, o tempo médio de deslocamento era de 20,5 minutos (para uma única viagem), enquanto que, para cidades com mais de 1 milhão de habitantes, esse tempo subia para 31,9 minutos. Porém, no caso norte-americano, os dados apresentados por Glaeser (1998, p. 151) também mostram que a correlação entre tamanho da cidade e tempo de deslocamento casa-trabalho caiu entre a década de 1980 e a de 1990, o que, para o autor, pode ser explicado pelos avanços na "tecnologia de tráfego", ou seja, melhorias na "precificação dos congestionamentos" (forma como indivíduos e formuladores de políticas públicas reagem a variações na frequência e intensidade dos congestionamentos, buscando compensá-los de alguma forma), e devido a melhorias no transporte público.

Existe, na literatura sobre o tema, uma vasta discussão, tradicionalmente chamada "commuting paradox" acerca de existência (ou inexistência) de um equilíbrio possível entre os gastos com habitação (terrenos e aluguéis) e os custos com transporte, isto é, como ambos se compensam (ou não) e quais são as consequências sobre o mercado de trabalho. Basicamente, há duas visões dominantes: (i) os que defendem que essa relação é mediada (e ajustada) por meio do valor ${ }^{5}$ do salário-hora, no sentido de que os rendimentos do trabalho embutem ou o custo dos terrenos/aluguéis mais próximos do trabalho ou os custos de transporte por residir mais longe, resultando em manutenção do nível de bem-estar; e (ii) os que acreditam que não existe equilíbrio via preços (aluguéis/ terras e salários), pois "rigidezes" e características idiossincráticas, como às relativas a questões familiares, como apontado por Cervero e Wu (1998) e peculiaridades do mer-

custo de vida é ao tamanho da cidade, ou seja, quanto o custo de vida varia quando variamos o tamanho da cidade, mantidas as demais variáveis estáveis.

5 Esse valor do salário-hora é ajustado pelo custo do tempo de deslocamento, que por sua vez é compensado tanto por um salário maior quando se trabalha longe do local de residência ou por um aluguel menor em regiões mais afastadas. 
cado imobiliários, de modo que existiria então um impacto negativo sobre o bem-estar gerado pelo maior tempo de deslocamento, como sugerem Stutzer e Frey (2008).

Van Ommeren e Gutiérrez (2010, p. 83) examinaram os efeitos da distância percorrida durante o deslocamento casa-trabalho sobre os padrões de oferta de trabalho, em especial sobre a oferta semanal de trabalho, o número de dias trabalhados e o número de horas trabalhadas por dia. Essa diferenciação é especialmente importante, uma vez que o deslocamento casa-trabalho representa um custo fixo para a oferta diária de trabalho, mas um custo variável para a oferta semanal, devido à escolha do número de dias trabalhados ${ }^{6}$. A inovação desse trabalho foi fazer com que as mudanças de distância fossem induzidas pelo empregador, mais precisamente devido a mudanças de localidade da empresa, o que supera o problema de a distância ser endógena em relação à oferta de trabalho.

Existe uma longa literatura (Gin e Sonstelie, 1992; Van Ommeren e Rietveld, 2005; Van Ommeren e Gutiérrez, 2010; Gibbons e Machin, 2006; Van Ommeren et al., 2000; entre outros) acerca da relação entre oferta de trabalho e custo de deslocamento.

Essa relação é de especial interesse da Ciência Econômica por três motivos:

i) Os policy makers têm interesse em saber se o congestionamento e a infraestrutura pública de transportes afetam a decisão das pessoas sobre quanto tempo elas passam no trabalho;

ii) A correlação entre os dois fatores pode ajudar a explicar padrões de longo prazo no tempo de deslocamento casa-trabalho (GIN e Sonstelie, 1992; Van Ommeren e Rietveld, 2005). Por exemplo, Black et al. (2008, p. 20) sugerem que a redução no custo do deslocamento, resultante de melhorias nas tecnologias de transportes e de mudanças nos padrões de habitação, impulsionaram o crescimento secular da oferta de mão de obra feminina; e

iii) Parte do custo do deslocamento é paga via perda de produtividade dos trabalhadores (Van Ommeren e Gutiérrez, 2010, p. 83).

Os efeitos do tempo de deslocamento sobre oferta de trabalho dependem da rigidez na oferta de trabalho e têm efeitos ambíguos. Quando o número de dias de trabalho é fixo, o custo de deslocamento é fixo e evidências indicam que o aumento do tempo de deslocamento pode levar à queda da oferta de trabalho. Porém, se os dias de

6 A variação no número de dias trabalhados na semana ou mesmo a variação no número de horas trabalhadas no dia não se aplicam à maior parte da população brasileira, uma vez que a legislação e os contratos preveem, em geral, um número fixo de horas diárias e uma semana regular de trabalho de segunda a sexta, que eventualmente inclui um ou mais sábados do mês. Porém, na Europa e nos EUA, esse tipo de arranjo é flexibilizado. 
trabalho, assim como o número de horas, forem flexíveis, pode ocorrer um aumento da oferta de trabalho. Além disso, o efeito poderia ser positivo também nos casos em que trabalhadores com alto custo de deslocamento chegam mais cedo ao trabalho e decidem sair mais tarde para evitar os congestionamentos, aumentando o número de horas trabalhadas (Van Ommeren e Gutiérrez, 2010, p. 82).

Alguns estudos, no entanto, defendem que esses efeitos sobre oferta de trabalho seriam fracos (Gibbons e Machin, 2006). "Most information we have about this relationship is indirect: most studies find that the commuters' value of travel time is rather low (about 50\% of their wage), suggesting that the effect of the length of the commute on labour supply may be rather weak" (Van Ommeren e Gutiérrez, 2010, p. 82).

Feita essa breve revisão da literatura, a próxima seção trata da questão do tempo de deslocamento de casa ao trabalho no contexto brasileiro, destacando alguns textos que a colocam como um problema metropolitano.

\section{CONTEXTO BRASILEIRO: TEMPO DE DESLOCAMENTO DE CASA AO TRABALHO COMO UMA QUESTÃO METROPOLITANA}

A análise da evolução histórica do tempo de deslocamento no Brasil revela, primeiramente, que o tempo de deslocamento no Brasil passou de 28,4 minutos em 1992 para 30,2 minutos em 2012, segundo o Ipea (2013, p. 10). Como pode ser visto na Tabela 1 , o tempo de deslocamento nas áreas metropolitanas é consideravelmente maior do que a média nacional em ambos os períodos.

Verifica-se ainda um crescimento do tempo de deslocamento em todos os recortes, padrão diferente do verificado na literatura americana, conforme apontado anteriormente, em que as regiões metropolitanas parecem estar respondendo melhor aos desafios de mobilidade urbana.

Tabela 1 - Tempo gasto no deslocamento casa-trabalho por localização de moradia

\begin{tabular}{lcccrrr}
\hline \multirow{2}{*}{ Local de Domicílio } & \multicolumn{3}{c}{ Minutos de casa ao trabalho } & \multicolumn{2}{c}{ Gastam mais de $\mathbf{1}$ hora até o trabalho (\%) } \\
\cline { 2 - 7 } & $\mathbf{1 9 9 2}$ & $\mathbf{2 0 1 2}$ & Variação (\%) & $\mathbf{1 9 9 2}$ & $\mathbf{2 0 1 2}$ & Variação (p.p.) \\
\hline Brasil & 28,4 & 30,2 & 6,4 & 8,2 & 10,4 & 2,19 \\
Áreas não-metropolitanas & 22,7 & 23,6 & 4,2 & 3,6 & 4,6 & 0,97 \\
Áreas metropolitanas & 36,4 & 40,8 & 12,1 & 14,6 & 18,6 & 4,02 \\
\hline
\end{tabular}

Fonte: IPEA (2013).

Observa-se ainda que trabalhadores residentes em áreas metropolitanas gastam significativamente mais tempo do que os residentes em áreas não metropolitanas. Essa disparidade aumentou entre 1992 e 2012, uma vez que a variação percentual no 
tempo de deslocamento foi quase três vezes maior para as regiões metropolitanas. A proporção de trabalhadores que despendem mais do que uma hora até o trabalho cresceu 4,02 pontos percentuais entre 1992 e 2012 nas regiões metropolitanas (RMs), o que sugere forte deterioração das condições de transportes nessas localidades.

O excessivo tempo gasto no trajeto casa-trabalho é, claramente, um problema nas regiões metropolitanas brasileiras e parece ser também uma questão tipicamente metropolitana, já que esse tempo foi, em média, $28 \%$ maior nessas regiões do que para o Brasil como um todo em 2012.

As RMs brasileiras, no entanto, guardam características muito distintas entre si, parcialmente em decorrência do tamanho do território brasileiro e dos padrões de desenvolvimento regionais extremamente desiguais. Os autores, então, abrem a sessão de resultados empíricos discutindo exatamente as diferenças materiais entre essas localidades.

Tabela 2 - Características das maiores regiões metropolitanas e do Distrito Federal - Brasil (2010)

\begin{tabular}{lcccccc}
\hline $\begin{array}{c}\text { Região } \\
\text { Metropolitana } \\
(\mathbf{R M})\end{array}$ & População & $\begin{array}{c}\text { Área total } \\
\left(\mathbf{K m}^{\mathbf{2}}\right)\end{array}$ & $\begin{array}{c}\text { Densidade } \\
\text { demográfica } \\
\left(\mathbf{h a b} / \mathbf{K m}^{\mathbf{2}}\right)\end{array}$ & $\begin{array}{c}\text { PIB per } \\
\text { capita } \\
(\mathbf{2 0 0 8})\end{array}$ & $\begin{array}{c}\text { Taxa de } \\
\text { motorização* }\end{array}$ & $\begin{array}{c}\text { Tempo médio } \\
\text { de deslocamento } \\
\text { casa-trabalho } \\
(\mathbf{e m} \text { minutos) }\end{array}$ \\
\hline São Paulo & 19.443 .745 & $7.943,80$ & $2.447,70$ & $30.349,52$ & 38,1 & 42,8 \\
Rio de Janeiro & 11.835 .708 & $5.643,80$ & $2.097,10$ & $19.762,04$ & 20,8 & 42,6 \\
Belo Horizonte & 4.883 .970 & $14.415,90$ & 338,8 & $19.540,41$ & 29,6 & 34,4 \\
Porto Alegre & 3.978 .470 & $9.800,20$ & 406 & $23.225,00$ & 31,2 & 27,7 \\
Recife & 3.870 .004 & $2.768,50$ & $1.397,90$ & $13.592,95$ & 15,3 & 34,9 \\
Fortaleza & 3.615 .767 & $5.783,60$ & 625,2 & $11.715,26$ & 14,7 & 31,7 \\
Salvador & 3.573 .973 & $4.375,10$ & 816,9 & $17.721,18$ & 16 & 33,9 \\
Curitiba & 3.223 .836 & $15.418,50$ & 209,1 & $22.953,67$ & 41,6 & 32,1 \\
Distrito Federal & 2.570 .160 & $5.801,90$ & 443 & $45.873,47$ & 37,3 & 34,8 \\
Belém & 2.101 .883 & $1.819,30$ & $1.155,30$ & $9.228,27$ & 11,2 & 31,5 \\
\hline
\end{tabular}

Notas: $\left(^{*}\right)$ Número de automóveis (carros, pick-ups, veículos utilitários esportivos, vans e minivans) para cada cem pessoas. $\left({ }^{* *}\right)$ Dados da PNAD de 2009.

Fonte: Elaboração própria com base em dados de Pereira e Schwanen (2013); Censos Demográficos 2000 e 2010 e PNAD (IBGE, 2001 e 2010 e vários anos); Registro Nacional de Veículos Automotores (RENAVAN), do Departamento Nacional de Trânsito (DENATRAN).

Ao analisarmos a Tabela 2, é possível perceber uma grande concentração populacional nas metrópoles das regiões Sudeste (São Paulo, Rio de Janeiro e Belo Horizonte) e Sul (Porto Alegre e Curitiba), comparativamente às regiões Norte (Belém) e Nordeste (Recife, Fortaleza e Salvador). Esse padrão não se verifica apenas no número de habitantes, mas também em outros aspectos socioeconômicos, como a renda per capita, que é, em média, 77\% maior nas regiões metropolitanas do Sul e do Sudeste em relação às do Norte e do Nordeste; e a taxa de motorização, que é maior do que 20 automóveis para cada 100 habitantes para todos os membros do primeiro grupo e 
abaixo desse mesmo valor para todos os membros do segundo grupo. Por fim, como reflexo de maiores taxas de densidade demográfica e motorização, as regiões metropolitanas do Sul e do Sudeste apresentam, em média, maiores tempos de deslocamento casa-trabalho. Mesmo assim, vale ressaltar que a disparidade nesse indicador não é tão intensa quanto nos demais, e que a região metropolitana de Curitiba se apresenta como um outlier, em decorrência de seu mais bem estruturado sistema de mobilidade urbana (Leitão, 2010).

O problema de mobilidade urbana nas regiões metropolitanas brasileiras fica evidente quando comparado a referências internacionais. O Gráfico 1 mostra a posição das principais RMs brasileiras em um ranking contendo apenas regiões metropolitanas com mais de dois milhões de habitantes em diversas localidades do mundo.

\section{Gráfico 1 - Tempo médio de deslocamento casa-trabalho - regiões metropolitanas selecionadas no Brasil e no mundo $\left(^{*}\right)(* *)$ (em minutos)}

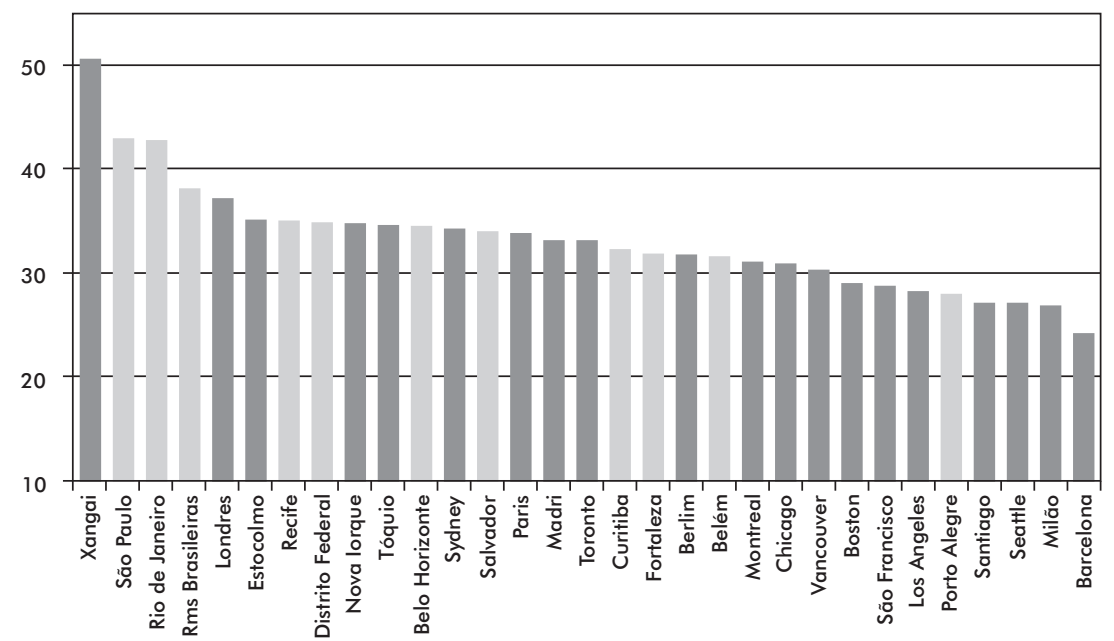

Notas: (*) Tóquio (2005); Santiago e Europa (2006); Brasil (2009); Austrália, Canadá, Xangai e Estados Unidos (2010). (**) Os critérios para delimitação das fronteiras das regiões metropolitanas europeias podem variar entre os países. Os dados para os Estados Unidos se baseiam nas regiões metropolitanas americanas (metropolitan statistical areas). Fonte: Pereira e Schwanen (2013).

Quando comparadas entre si em termos de tempo de deslocamento casa-trabalho, as disparidades entre as RMs brasileiras tornam-se ainda mais evidentes. Antes de passar para a análise desse quadro, a seção seguinte apresenta os preliminares empíricos, descrevendo a base de dados, o universo e as variáveis de análise. Pereira e Schwanen (2013, p. 14) destacam que, para o ano de 2009, as regiões metropolitanas do Rio de Janeiro e São Paulo possuíam viagens 31\% mais demoradas do que as das demais RMs. 
Tabela 3 - Percentual de trabalhadores e tempos de percurso casa-trabalho por região metropolitana

\begin{tabular}{lcccccc}
\hline \multirow{2}{*}{ Local de domicílio } & \multicolumn{3}{c}{ Minutos de casa ao trabalho } & \multicolumn{2}{c}{ Gastam mais de uma hora até o trabalho (\%) } \\
\cline { 2 - 7 } & $\mathbf{1 9 9 2}$ & $\mathbf{2 0 1 2}$ & Variação (\%) & $\mathbf{1 9 9 2}$ & $\mathbf{2 0 1 2}$ & Variação (p.p.) \\
\hline Distrito Federal & 32,8 & 34,9 & $6,5 \%$ & $8,7 \%$ & $10,6 \%$ & 1,97 \\
Belém & 24,3 & 32,8 & $35,4 \%$ & $3,3 \%$ & $10,1 \%$ & 6,86 \\
Belo Horizonte & 32,4 & 36,6 & $13,0 \%$ & $10,6 \%$ & $15,7 \%$ & 5,02 \\
Curitiba & 30,2 & 32,0 & $6,0 \%$ & $8,6 \%$ & $11,3 \%$ & 2,70 \\
Fortaleza & 30,9 & 31,7 & $2,8 \%$ & $8,1 \%$ & $9,8 \%$ & 1,69 \\
Porto Alegre & 27,9 & 30,0 & $7,6 \%$ & $6,1 \%$ & $7,8 \%$ & 1,70 \\
Recife & 32,3 & 38,0 & $17,8 \%$ & $9,6 \%$ & $14,0 \%$ & 4,41 \\
Rio de Janeiro & 43,6 & 47,0 & $7,8 \%$ & $22,2 \%$ & $24,7 \%$ & 2,51 \\
Salvador & 31,2 & 39,7 & $27,1 \%$ & $8,3 \%$ & $17,3 \%$ & 8,97 \\
São Paulo & 38,2 & 45,6 & $19,6 \%$ & $16,6 \%$ & $23,5 \%$ & 6,83 \\
\hline
\end{tabular}

Fonte: Ipea (2013).

A Tabela 3 permite uma visualização da piora do sistema de mobilidade urbana das RMs brasileiras, a partir dos cálculos do Ipea. Em 2012, a região metropolitana do Rio de Janeiro apresenta o maior tempo de deslocamento casa-trabalho do Brasil, seguida de perto pela região metropolitana de São Paulo. Para explicar o desempenho da região metropolitana de Porto Alegre, o Ipea (2013, p.10) elenca como "hipóteses explicativas a configuração da metrópole, que apresenta melhor distribuição das atividades econômicas, e, consequentemente, dos empregos, em toda a sua área, além dos atributos positivos do sistema de trânsito e transporte da RM". As regiões metropolitanas de Belém e Salvador se destacam pela elevação no tempo médio de deslocamento casa-trabalho, no período apresentado, muito acima das demais RMs, 35,4\% e 27,1\%, respectivamente. A região metropolitana de Fortaleza surpreende pelo desempenho no período, superior, inclusive, ao registrado na região metropolitana de Curitiba, tido como referência nacional no que diz respeito a mobilidade (Leitão, 2010).

\section{PRELIMINARES EMPÍRICOS}

\subsection{BASE DE DADOS}

O presente trabalho utilizará uma abordagem semelhante à empregada por Pereira e Schwanen (2013), de modo que serão utilizados os dados disponíveis nas Pesquisas Nacionais por Amostra de Domicílios dos anos de 1992 atualizados até 2013, último ano disponível da pesquisa. Conforme destacado pelos dois autores, a PNAD não é uma pesquisa sobre transportes no molde das pesquisas domiciliares de origem/destino (OD), não contando, por exemplo, com informações sobre deslocamentos que não se- 
jam no sentido casa-trabalho, ou informações sobre a qualidade dessas viagens. Porém, diferentemente dessas últimas, conta com algumas vantagens que são extremamente úteis para o caso das regiões metropolitanas brasileiras, uma vez que a PNAD: (1) cobre todas as regiões metropolitanas brasileiras, e não apenas áreas urbanas específicas, como as pesquisas OD; (2) possui uma amostra estatisticamente representativa para as nove principais regiões metropolitanas do país e o Distrito Federal (bem como para o nível nacional, estadual e municipal); (3) é aplicada em todo o país utilizando a mesma metodologia; (4) inclui uma vasta gama de informações adicionais sobre o perfil do indivíduo e do domicílio, como características sociais, econômicas e demográficas, tais como posse de veículos privados e auxílio-transporte recebido pelos trabalhadores; (4) está disponível ao público; e (5) é realizada com regularidade ${ }^{7}$, criando-se a possibilidade de acompanhar tendências históricas, o que consiste no objetivo último desse trabalho.

\subsection{UNIVERSO DE ANÁLISE}

No tratamento dos dados seguiram-se os critérios sugeridos em Pereira e Schwanen (2013, p. 12), não sendo considerados: (a) indivíduos residentes em domicílios que estavam no mesmo terreno ou área do estabelecimento no qual trabalhavam; (b) indivíduos de áreas rurais; (c) aqueles que possuem jornada de trabalho totalmente compreendida no período noturno de 10 horas da noite às cinco horas da manhã seguinte; (d) trabalhadores que exerciam atividades em fazendas, sítios, granjas, chácaras etc.; (e) pessoas empregadas em atividades de agricultura ou de extrativismo e mineração; (f) residentes fora das regiões metropolitanas; e (g) com idade não contida entre 15 e 64 anos $^{8}$.

O total de observações levadas em consideração na análise após a aplicação dos filtros acima listados varia de aproximadamente 23 mil em 1993 a 30 mil em 2013. A proporção desse grupo focal dentro da amostra original da PNAD se mantém aproximadamente constante em torno de $8 \%$.

\footnotetext{
A PNAD não foi aplicada nos anos de 1994, 2000 e 2010 por conta da aplicação do censo demográfico.

8 Como se trata de uma análise de mobilidade focada no trabalhador metropolitano, foi definida a faixa etária de 15 a 64 anos. Pessoas com idades iguais e inferiores a 15, bem como os maiores de 65 anos, têm baixa participação no mercado de trabalho urbano, não sendo essas faixas etárias estatisticamente significativas (Mihessen, 2014, p. 60).
} 


\subsection{VARIÁVEIS DE ANÁLISE}

As nove principais regiões metropolitanas consideradas foram as seguintes: Belém (RMPA), Fortaleza (RMFOR), Recife (RMRE), Salvador (RMSA), Belo Horizonte (RMBH), Rio de Janeiro (RMRJ), São Paulo (RMSP), Curitiba (RMCUR) e Porto Alegre (RMPOA), além do Distrito Federal (RMDF).

As principais variáveis utilizadas neste trabalho, para além das necessárias à construção dos filtros supracitados, foram: sexo (V0302), cor ou raça' (V0404), recebimento de auxílio-transporte (V9045), posto de trabalho ${ }^{10}$ (V4706), rendimento mensal domiciliar (V4721), número de pessoas por domicílio (V4724), essas duas últimas a fim de compor uma terceira variável, o rendimento mensal domiciliar per capita ${ }^{11}$, e o tempo de deslocamento casa-trabalho (V9057).

Para o cálculo do tempo médio de deslocamento, seguiu-se o mesmo método utilizado em Pereira e Schwanen (2013, p. 11), no qual o "tempo médio de deslocamento das viagens foi calculado utilizando o ponto médio de cada categoria intermediária e o primeiro ponto da última categoria aberta, conforme sugerido em Bussab e Morettin (1987)". Uma vez que a variável V9057 (tempo de percurso diário de ida da residência para o local de trabalho) é construída como variável categórica com quatro intervalos, a saber, (i) até trinta minutos, (ii) entre trinta e uma hora, (ii) entre uma hora e duas horas e (iv) duas horas ou mais, os pontos médios utilizados foram, respectivamente, 15 minutos; 40,5 minutos; 90,5 minutos e 121 minutos.

A próxima seção abordará todas as regiões metropolitanas conjuntamente, porém tentando identificar como o tempo médio de deslocamento de casa ao trabalho varia de acordo com sexo, cor, renda e tipo de posto de trabalho. Será feita também uma análise do tempo de deslocamento de casa ao trabalho para o país como um todo e desagregado por RM, buscando observar quais são as grandes tendências e as especificidades regionais.

9 Contendo a seguinte divisão: brancos, pretos, amarelos, pardos, indígenas ou sem declaração. Para efeitos de análise, foram desconsiderados os indivíduos sem declaração. Amarelos e indígenas representam uma fração pouco significativa dentro da população brasileira, em especial no subgrupo focalizado neste trabalho, tendo-se optado por sua remoção. Seguiu-se também uma prática comum ao se trabalhar com esse tipo de dado, que é a de unificar pretos e pardos.

${ }_{10}$ Os postos de trabalho podem ser subdivididos em dois grupos. Os postos formais de trabalho incluem: empregados com carteira assinada, militares, funcionários públicos estatutários e trabalhadores domésticos com carteira de trabalho assinada. Todos os demais, isto é, trabalhadores domésticos sem carteira assinada, conta própria, empregadores, trabalhadores não remunerados, trabalhadores na produção para o próprio consumo, trabalhadores na construção para o próprio uso e outros empregados sem carteira assinada, foram classificados como não formais.

11 O rendimento mensal domiciliar per capita não faz parte do conjunto de variáveis originais da PNAD, tendo sido necessário para sua criação dividir o rendimento mensal domiciliar pelo número de membros do domicílio. Todos os rendimentos declarados sofreram as correções monetárias necessárias. 


\section{EVOLUÇÃO DO TEMPO MÉDIO DE DESLOCAMENTO DE CASA AO TRABALHO POR REGIÃO METROPOLITANA ENTRE 1992 E 2013}

A análise da evolução do tempo de deslocamento de casa ao trabalho mostra, primeiramente, que durante todo o período analisado, as regiões metropolitanas apresentam um tempo médio de deslocamento de casa ao trabalho significativamente superior à média brasileira, conforme pode ser visto no Gráfico $2^{12}$. Essa diferença permaneceu em torno de $23 \%$ até 2006 , quando começou gradativamente a elevar-se, revelando comportamento diferente do que tem se verificado nos estudos internacionais, que apresentam estabilidade do tempo médio de deslocamento de casa ao trabalho.

\section{Gráfico 2 - Tempo de deslocamento casa-trabalho - Brasil e regiões metropolitanas - 1992-2013 (em minutos)}

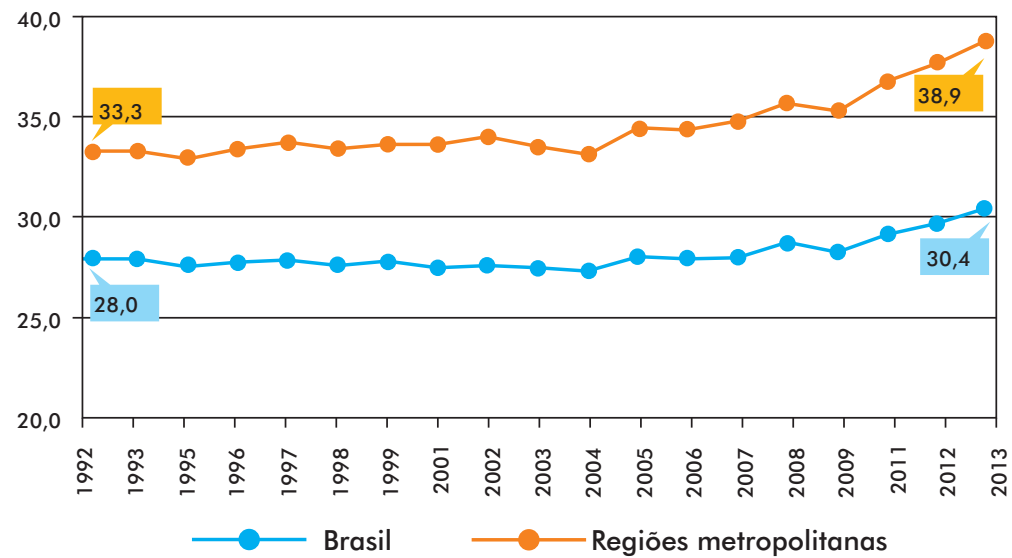

Fonte: PNAD/IBGE

Essa média, no entanto, pode estar refletindo diferentes padrões (ou não) entre as regiões metropolitanas brasileiras. Conforme pode ser visto nos gráficos 3 a 5 , as RMs do Sudeste possuem os maiores tempos de deslocamento casa-trabalho. Os casos mais críticos são os da RMRJ (50 minutos) e da RMSP (47 minutos), nas quais, em 2013, os tempos de viagem foram em média $34 \%$ mais longos do que nas demais.

12 Diferenças nos valores apresentados ao longo deste trabalho e os observados em Pereira e Schwanen (2013) decorrem, essencialmente, da definição do ponto médio das faixas de tempo de deslocamento. Para a elaboração deste trabalho foram $15 \mathrm{~min}, 40,5 \mathrm{~min}, 90,5 \mathrm{~min}$ e $121 \mathrm{~min}$. Enquanto no artigo de Pereira e Schwanen (2013) os valores escolhidos foram, respectivamente, $20 \mathrm{~min}, 40 \mathrm{~min}, 90 \mathrm{~min}$ e $120 \mathrm{~min}$. Adicionalmente, pode haver diferenças relativas aos filtros aplicados no tratamento dos dados das PNADs. 


\section{Gráfico 3 - Tempo de deslocamento casa-trabalho - RMBH, RMRJ e RMSP - 1992- 2013 (em minutos)}

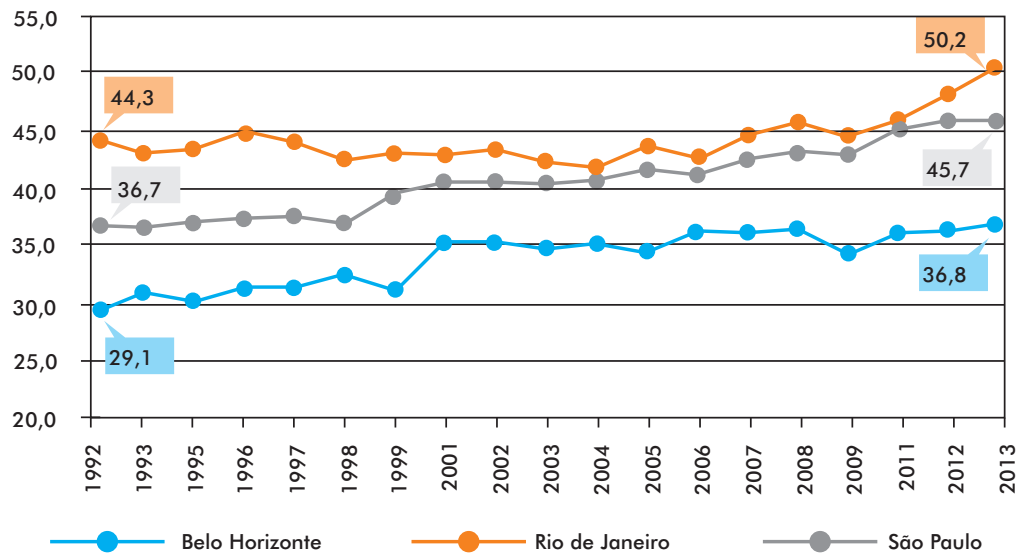

Fonte: PNAD/BBGE.

Ao longo dessas duas décadas, cada RM apresentou comportamento específico, mas sempre com uma tendência de elevação do tempo médio de deslocamento de casa ao trabalho. Durante o período 1992-2004, as condições de transporte urbano na RMSP parecem ter piorado, o que encurtou a diferença em relação a RMRJ. Porém, desde 2011, a RMRJ iniciou uma vigorosa trajetória de elevação, que culminou no rompimento da marca de 50 minutos em 2013, ao mesmo tempo que a RMSP se estabilizou em torno dos 45 minutos. Após um forte aumento no tempo de deslocamento entre 1999 e 2001, a $\mathrm{RMBH}$ alcançou o que parece ser um novo platô, em torno de 36 minutos.

No Gráfico 4, com exceção da RMFO, todas as demais apresentaram tendência geral de aumento, com especial destaque para a RMPA, que registrou crescimento acumulado de $70,4 \%$ no período, o que corresponde a um aumento médio de $3 \%$ no tempo de deslocamento a cada ano.

As regiões metropolitanas do Nordeste chamam atenção por dois motivos: (1) a RMSA e a RMRE em 2012 e 2013, respectivamente, romperam a marca dos 40 minutos, o que só havia sido observado até então na RMRJ e na RMSP - as taxas médias de crescimento anual (do tempo de deslocamento) dessas duas regiões são a segunda e a terceira maiores do país, respectivamente, ou seja, a RMSA (1,45\% a.a.) e a RMRE (1,32\% a.a.) têm visto seus tempos de deslocamento casa-trabalho crescerem mais do que RMSP (1,23\% a.a.) e RMRJ (0,70\% a.a.) -, e (2) a RMFO apresenta um desempenho praticamente estável ao longo do período, tendo o tempo de deslocamento crescido apenas $1,42 \%$ entre 1992 e 2013. Esse intrigante resultado aponta a importância de futuros trabalhos que investiguem quais foram as políticas públicas ou características sociogeográficas que contribuíram para a estabilidade do tempo médio ao longo de mais de duas décadas. 


\section{Gráfico 4 - Tempo de deslocamento casa-trabalho - RMFO, RMRE, RMSA e RMPA - 1992-2013 (em minutos)}

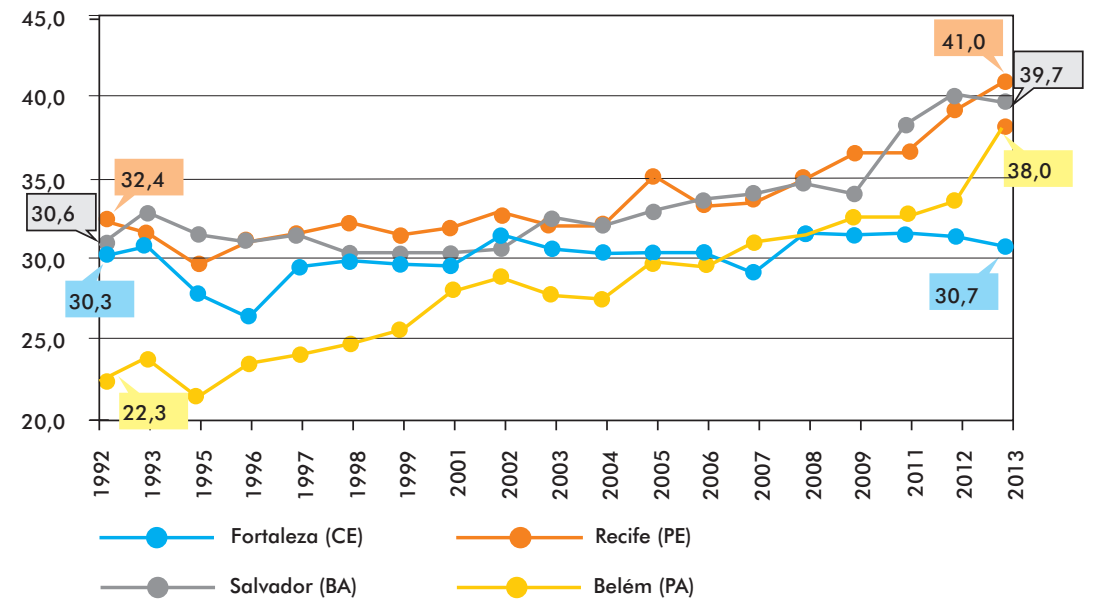

Fonte: PNAD/IBGE

O Gráfico 5 reúne a RMCUR, a RMPOA e a RMDF. Essa última apresenta valores bastante voláteis ao longo do tempo, e a partir de 2007 iniciou uma trajetória de acentuado aumento. As RMs do Sul do Brasil têm mostrado menores oscilações e uma tendência de aumento mais suave no longo prazo do que as demais regiões metropolitanas do país.

Gráfico 5 - Tempo de deslocamento casa-trabalho - RMCUR, RMPOA e RMDF - 19922013 (em minutos)

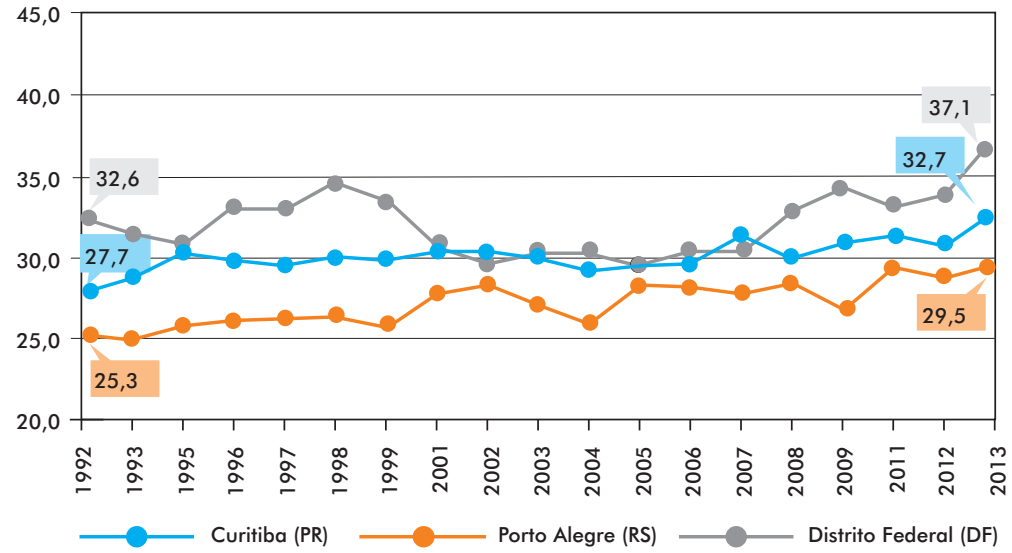

Fonte: PNAD/IBGE. 
Quando se comparam as regiões metropolitanas em uma perspectiva de longo prazo (1992-2013), verifica-se que as RMs do Nordeste e a RMPA têm apresentado uma tendência geral e persistente de elevação no tempo de deslocamento, convergindo, em algum grau, para valores mais próximos dos das RMs Sudeste, exceto a RMFO. Ao mesmo tempo, as RMs do Sul do país apresentam alguma estabilidade ao longo do tempo, mas sem uma tendência clara. O caso de DF é marcado por irregularidades, tendo apresentado certa estabilidade até 2007, quando iniciou uma escalada no tempo de deslocamento acentuada no último ano.

Pereira e Schwanen (2013, p. 16) já haviam demonstrado que existia no Brasil uma tendência geral de aumento na proporção de viagens longas (com mais de uma hora de duração) em áreas metropolitanas até 2009, com diferentes trajetórias entre as RMs. Ao analisar a proporção das viagens casa-trabalho com mais de uma hora de duração, mais especificamente o caso da RMRJ, haviam demonstrado que voltou a subir a partir da segunda metade dos anos 2000, elaborando duas hipóteses interessantes: (1) a recente piora no indicador pode ter se dado por conta do aumento da frota de veículos e das taxas de motorização associados ao crescimento econômico visto na região, bem como da expansão de bairros residenciais mais afastados, onde, portanto, as distâncias são maiores em relação à região central; e (2) aumentar a capacidade da infraestrutura de transportes trará efeitos positivos no curto prazo, porém, esses efeitos se dissipam no tempo à medida que a demanda por vias volta a se aproximar do ponto de saturação que inicialmente fomentou o investimento de melhoramento da infraestrutura.

Ao mesmo tempo, a RMSP e a RMBH fornecem exemplos de como investimentos em mobilidade nem sempre refletem em melhora nas condições de transporte, em termos de tempo de deslocamento de casa ao trabalho. A proporção de longas viagens casa-trabalho cresceu nas duas RMs de forma contínua no período analisado, a despeito de diversos projetos de infraestrutura de transportes (dezenas de novas estações de trem e metrô inauguradas). Na visão dos autores, a diferença para o que se viu no caso da RMRJ reside no fato de que os investimentos na RMSP e na RMBH não foram tão concentrados no tempo, de modo que foram capazes, tão somente, de atender parte do crescimento da demanda por transportes nessas regiões.

A proporção de viagens com mais de uma hora de duração na RMSA, RMRE, RMFOR e RMPA aumentou significativamente, em especial na RMPA e na RMSA. Esse resultado reforça a ideia de que essas RMs estariam convergindo para níveis próximos aos registrados na região Sudeste do país. Esse fenômeno é especialmente preocupante na medida em que ainda existe grande margem para o crescimento da taxa de motorização dessas regiões, que, como mostrado por Pereira e Schwanen (2013, p. 17), é metade das observadas nas regiões mais desenvolvidas. É interessante notar, no en- 
tanto, que a RMFOR tem um comportamento recente diferente, com diminuição da proporção de trabalhadores que passam mais de uma hora no deslocamento de casa ao trabalho, sendo segunda RM com menor tempo de deslocamento.

Por fim, Pereira e Schwanen (2013, p. 18) afirmam que, embora haja peculiaridades nas dinâmicas de cada RM, o que se observa é um aumento gradual na proporção de longas viagens, em especial entre 2005 e 2009, à exceção da RMCUR e da RMPOA, onde, provavelmente, os sistemas de transportes são mais eficientes. Destacam também que esse fenômeno possui múltiplas causas: crescimento da população, aumento das taxas de motorização, investimentos em sistemas de transporte de massa, mudanças no uso do solo e a expansão urbana, carecendo, portanto, de uma abordagem multidisciplinar, além de destacar a explicação de um aparente movimento "cíclico" observado em alguns períodos em diversas regiões metropolitanas.

O foco deste trabalho não é discutir os determinantes históricos e regionais presentes por trás das trajetórias das diferentes regiões metropolitanas do país, mas sim tão somente apresentar um amplo quadro geral da mobilidade urbana nos principais centros populacionais do país. Fogem, portanto, do escopo do trabalho questões mais técnicas como ampliações de vias metroviárias, rodoviárias ou demais obras regionais de infraestrutura de tráfego ${ }^{13}$.

\section{DIFERENÇAS NO TEMPO DE DESLOCAMENTO DE CASA AO TRABALHO POR CARACTERÍSTICAS SOCIOECONÔMICAS}

\subsection{DIFERENÇAS POR NÍVEL DE RENDA E A QUESTÃO DA EXCLUSÃO SOCIAL}

Diversos estudos internacionais já apontaram a existência de uma vulnerabilidade relativa a desvantagens no transporte urbano, isto é, existiria uma "exclusão social" em termos de mobilidade, que fica evidente nas diferenças de acesso ao sistema de transporte urbano entre as camadas mais ricas e as mais pobres da sociedade (Lucas, 2012, p.3).

No caso específico das metrópoles brasileiras ${ }^{14}$, Pero e Mihessen (2013) demonstraram que as camadas mais pobres da sociedade sofrem relativamente mais

13 Para um breve apanhado acerca desses tipos de melhorias nos sistemas de tráfego urbano, ver Pereira e Schawasen (2013).

14 Embora o trabalho seja focado na RMRJ, os autores buscaram contextualizar os resultados comparando-os com os observados em outras RM do país. O enfoque mais acentuado nessa região em específico ocorre, em parte, devido ao fato desta apresentar os piores resultados, comparativamente a outras regiões. 
com as desvantagens de transporte urbano do que as mais ricas. Essas desvantagens têm dupla dimensão: além de sofrerem com maiores tempos de deslocamento, os mais pobres também comprometem uma parcela maior de sua renda familiar com os gastos de transporte público. No caso da RMRJ, a situação é ainda mais grave entre os $20 \%$ mais pobres e moradores da periferia, grupo para o qual o peso do gasto com transporte público é extremamente alto e crescente ao longo do período analisado.

Para Levitas et al. (2007, p. 9), o fenômeno da exclusão social pode ser entendido como a falta ou a negação de acesso a recursos, direitos, bens e serviços, e a incapacidade de participar das relações e atividades normais, disponível para a maioria das pessoas em uma sociedade, seja em arenas econômicas, sociais, culturais ou políticas. A mobilidade urbana, enquanto direito ou serviço, se encaixa perfeitamente nesse conceito multidimensional, em especial devido ao seu papel central na determinação do padrão de inserção do indivíduo no mercado de trabalho e também como forma de acesso a outros serviços.

No contexto da mobilidade urbana, a exclusão de grupos específicos da população pode ser relacionada às características, ou dimensões, do sistema de transporte: (a) exclusão física: ocorre quando existem barreiras físicas de acesso ao sistema, como ausência de instalações apropriadas para deficientes, designs não adaptáveis de veículos ou até mesmo a falta de informação sobre os horários das viagens; (b) exclusão geográfica: o local onde as pessoas vivem influencia seu acesso ao sistema de transporte, como em áreas rurais ou as periferias dos centros urbanos; (c) exclusão dos centros de serviços e comércio: a distância em relação a mercados, escolas, serviços de saúde e lazer também impede seu acesso ao sistema de transporte urbano; (d) exclusão econômica: os custos monetários das viagens ou desemprego (e seus impactos sobre a renda) podem ser impeditivos ou limitadores do acesso ao sistema; (e) exclusão por falta de tempo: outras demandas, como dupla jornada, serviços domésticos e cuidado dos filhos podem reduzir o tempo disponível para viagens; (f) exclusão por medo: o receio quanto à violência ou à segurança pessoal durante a utilização do sistema de transporte pode reduzir sua demanda; e (g) exclusão espacial: ocorre quando a segurança ou o gerenciamento de espaços impede certos grupos de acessar locais públicos, como, por exemplo, condomínios fechados ou sala de espera de primeira classe (Church et al., 2000, p. 198).

O Gráfico 6 tenta evidenciar parte desse efeito. Nele são apresentados os tempos de deslocamento casa-trabalho para cada decil de renda da população das regiões metropolitanas em dois momentos, no biênio 1992-1993 e 2012-2013, ou seja, duas décadas depois. 
Como era de se esperar, a parcela mais pobre da população (primeiro decil) leva um tempo de deslocamento maior do que a mais rica (décimo decil). Em 2013, as viagens dos mais pobres demoravam, aproximadamente, $20 \%$ mais do que as dos mais ricos. Em uma perspectiva de longo prazo, os dados sugerem que houve uma pequena redução nessa diferença, que era de 25\% no biênio 1992-1993. Como pode ser observado no gráfico, houve um deslocamento para cima da curva para todos os decis de renda, o que significa uma deterioração das condições de transporte urbano, ao mesmo tempo que houve redução das desigualdades entre os dois extremos da população em termos de renda. Ao compararmos a evolução de cada um dos dois grupos ao longo do tempo, percebe-se que essa redução é proveniente de um aumento maior no tempo de deslocamento dos mais ricos: enquanto os mais pobres registraram um aumento de $15,8 \%$ no seu tempo de deslocamento, o decil mais rico da população observou uma elevação de $21 \%$ no tempo gasto no trajeto casa-trabalho, o que pode estar relacionado à maior utilização de veículos motorizados individuais por essa parcela da população, que estaria sofrendo com um "efeito congestionamento".

\section{Gráfico 6 - Tempo de deslocamento casa-trabalho por decil de renda* - Brasil e Regiões Metropolitanas - 1992-1993 e 2012-2013 (em minutos)}

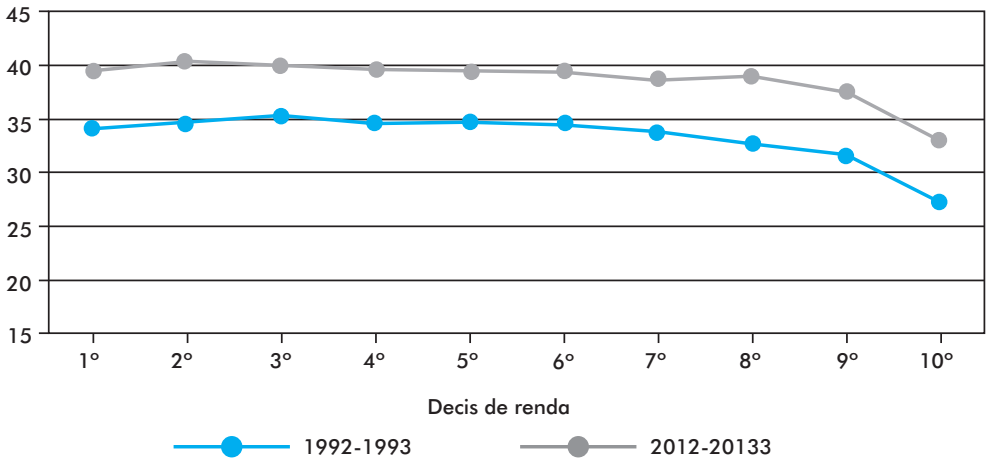

Nota: ${ }^{(*)}$ Decis de renda domiciliar per capita. Fonte: PNAD/IBGE.

O Gráfico 7 apresenta o tempo médio de deslocamento dos dois grupos em cada região metropolitana, para o conjunto delas e para o Brasil no período 2012-2013. Para todas essas regiões, a média da população registra um tempo de viagem mais próximo do decil mais pobre do que do decil mais rico e, em alguns casos, como Salvador e Recife, a média supera ambos os decis. Esse fenômeno sugere que os trabalhadores de renda média, isto é, aqueles dos decis centrais, também têm sofrido com a deterioração dos sistemas de transporte urbano. 


\section{Gráfico 7 - Tempo de deslocamento casa-trabalho do primeiro e do décimo decil de renda - Brasil e regiões metropolitanas - 2012-2013 (em minutos)}

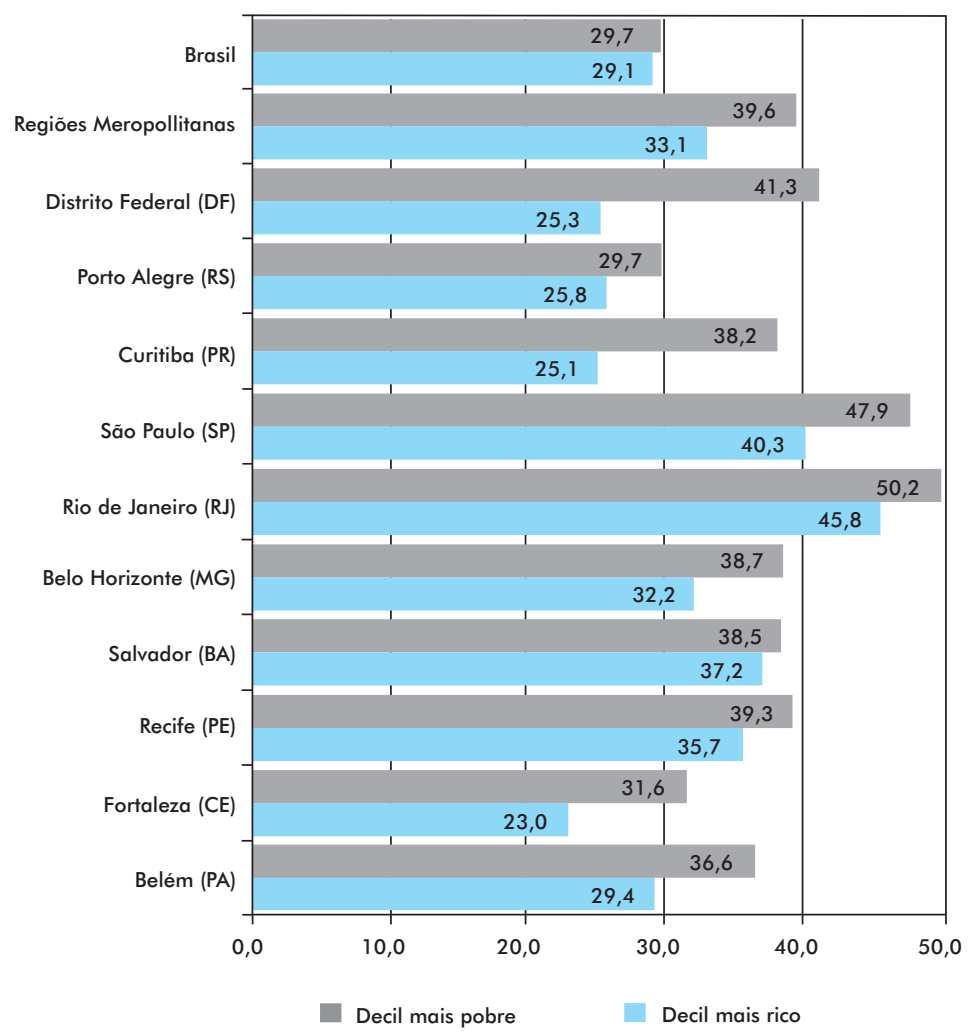

Fonte: PNAD/IBGE.

O Gráfico 8 ordena cada uma das áreas de acordo com a diferença entre o tempo gasto pelos mais pobres e pelos mais ricos no biênio 2012-2013. As RMs que apresentam maior desigualdade são as do Distrito Federal e a de Curitiba, onde os mais pobres fazem, em média, viagens $63 \%$ e 52\% mais demoradas do que os mais ricos, respectivamente. Novamente, a comparação entre o desempenho das regiões metropolitanas tomadas em conjunto e o desempenho em nível nacional sugere que o fenômeno da exclusão social no transporte urbano é uma marca típica das RMs.

Com base no Gráfico 8, observa-se que a diferença no tempo de deslocamento aumentou nas RMDF, RMCUR, RMFOR e RMPA e diminuiu nas demais. O caso da RMRJ chama a atenção, pois em 1992-1993, esta possuía a segunda maior diferença e passou para a terceira menor entre as RMs. Houve forte convergência também na RMRE e na RMSA. 
Gráfico 8 - Diferença no tempo de deslocamento casa-trabalho entre o primeiro e o décimo decil - Brasil e regiões metropolitanas - 1992-1993 e 2012-2013 (em minutos)

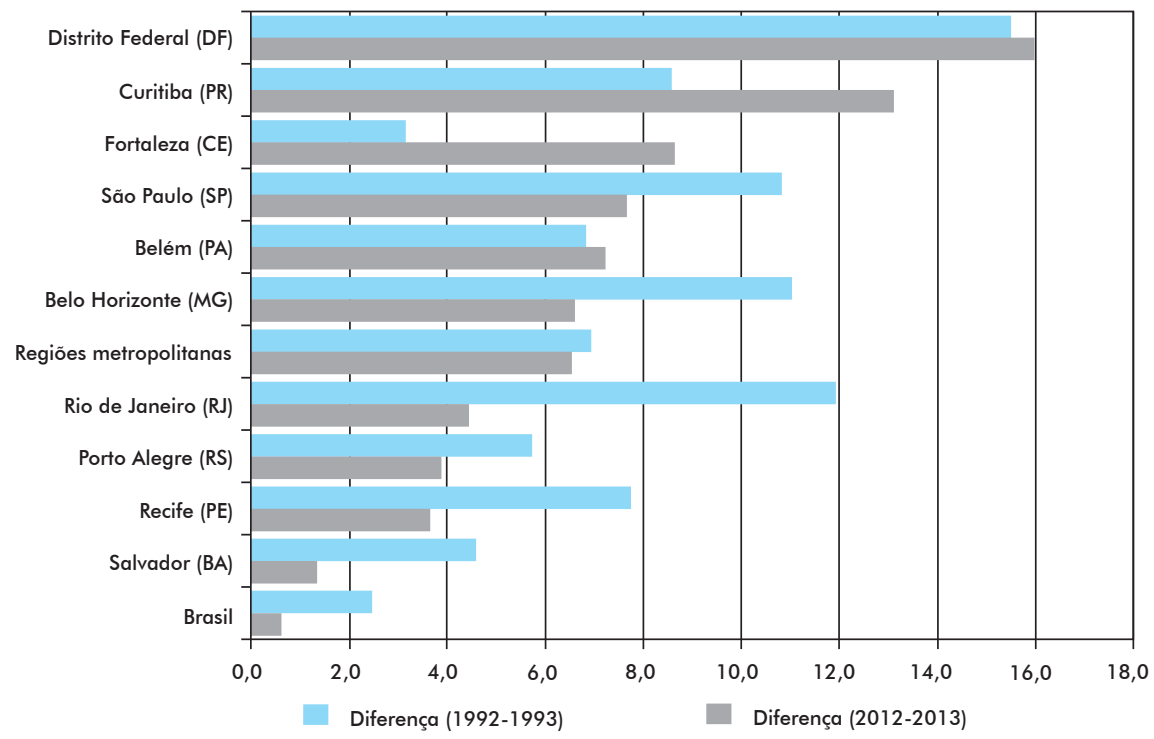

Fonte: PNAD/IBGE.

Com relação à proporção de viagens casa-trabalho com mais de uma hora de duração, os resultados são muito parecidos com os padrões observados no tempo de deslocamento. Em 1992-1993, 13,8\% dos trabalhadores mais pobres faziam viagens mais demoradas do que uma hora (apenas trajeto de ida para o trabalho), enquanto os mais ricos eram apenas 6,9\%. Já no biênio 2012-2013, 19,7\% dos trabalhadores do primeiro decil enfrentam mais de uma hora de deslocamento para ir ao trabalho, enquanto esse número, para os mais ricos, é de 12,7\%. Em termos absolutos, a evolução da representatividade dessa categoria de viagem foi muito próxima, aproximadamente, 6 p.p. para ambos os grupos na comparação entre os dois períodos. Entretanto, em termos relativos, o aumento foi muito mais significativo no grupo de alta renda.

Se a população das RMs for dividida em centis, é possível focalizar melhor a questão da exclusão social do transporte, uma vez que se torna possível enxergar a situação do $1 \%$ mais pobre. Nesse grupo, em 2013, 54,3\% dos trabalhadores faziam viagens de até 30 minutos, 28,8\% demoravam entre 30 minutos e uma hora para chegar ao trabalho e apenas $16,9 \%$ levavam mais do que uma hora. Isso sugere que esse grupo tem uma distribuição muito próxima à dos centis de renda mais elevada (do 90 em diante), porém, provavelmente, por motivos contrários: como sua renda é baixa, os custos de transporte até as áreas centrais podem ser impeditivos, de modo que esses trabalhadores restringem seu raio de procura por emprego para localidades mais próximas. 
O que se pode concluir é que houve, no período analisado, uma deterioração das condições de transporte nas regiões metropolitanas de forma generalizada, refletida em maiores tempos de deslocamento, com consequências mais graves sobre os trabalhadores do primeiro e segundo decil, bem como entre os acima do oitavo decil. Os decis centrais (terceiro ao sétimo) foram menos afetados, embora seus tempos de deslocamento sejam mais altos e tenham aumentado, em média, 15\% no período.

\subsection{DIFERENÇAS ENTRE HOMENS E MULHERES}

A análise de diferenciais no tempo de deslocamento por gênero no Brasil corrobora os resultados obtidos para os países desenvolvidos: homens gastam mais tempo para ir de casa ao trabalho do que mulheres (OECD, 2011). Entretanto, essa diferença vem se reduzindo, em especial após os anos 2000. Em 1992, homens levavam 4,5 minutos a mais do que as mulheres no trajeto de ida para o trabalho, o que equivale a uma diferença de $14,6 \%$. No ano de 2013, essa diferença é de apenas 3,6\%, ou 1,4 minutos.

\section{Gráfico 9 - Tempo de deslocamento casa-trabalho segundo sexo - regiões metropolitanas - 1992-2013 (em minutos)}

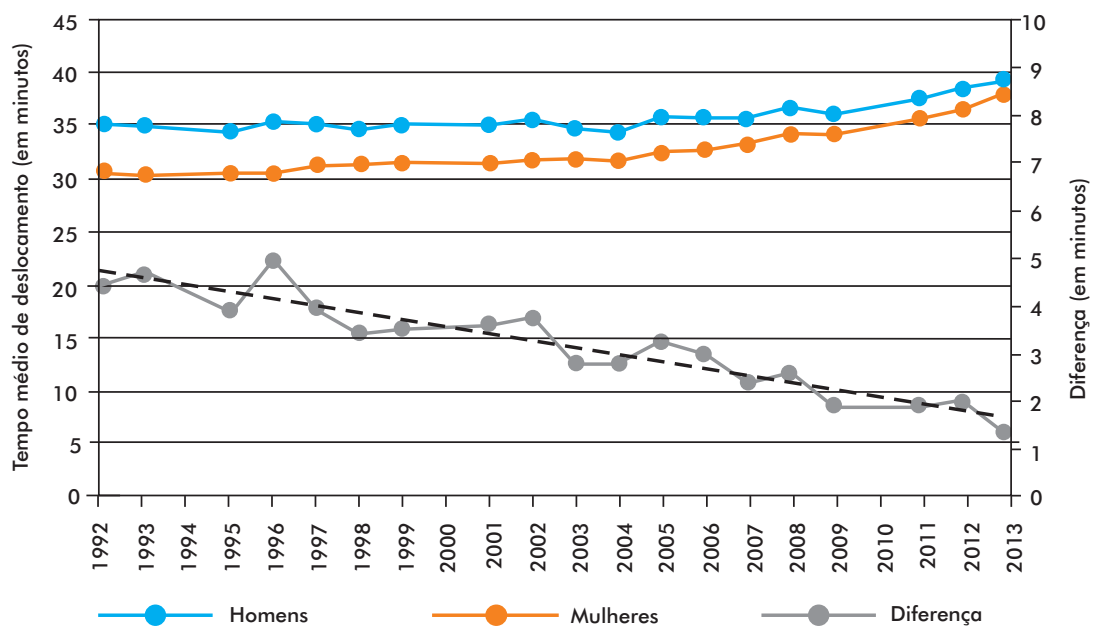

Fonte: PNAD/IBGE.

A diferença em minutos entre os dois grupos (representada pela linha cinza no Gráfico 9) tem uma clara tendência de queda no longo prazo. Comparando à taxa de crescimento acumulada no período 1992-2013, percebe-se que, enquanto o tempo de desloca- 
mento masculino cresceu, aproximadamente, $13 \%$, o feminino aumentou em quase $25 \%$. Isso significa que o diferencial entre os dois grupos tem diminuído mais devido ao aumento no tempo de viagem feminino do que por uma redução no tempo dos homens.

Como destacado por Pereira e Schwanen (2013), esse resultado é compatível com as mudanças sociodemográficas observadas no Brasil nos últimos 20 anos: (1) redução nas taxas de fecundidade; (2) mudanças na composição familiar, ou seja, mais famílias chefiadas por mulheres (principal provedora) e menos filhos; (3) aumento do nível educacional feminino; e (4) elevação da participação feminina no mercado de trabalho.

Esse resultado, no entanto, é diferente do registrado nos Estados Unidos, por exemplo. Conforme dito anteriormente, diversos estudos (McLafferty e Preston, 1996; Crane, 2007; Crane e Takahashi, 2009) concluem que esse movimento de redução tendencial na diferença de tempo de deslocamento entre sexos não ocorreu no mesmo ritmo visto no Brasil. Essa diferença permaneceu praticamente constante durante a década de 1980 (McLafferty e Preston, 1996), e aumentou, embora pouco, entre 1985 e 2005, não havendo evidências empíricas que sustentem a tese da "revolução silenciosa" entre as mulheres. As explicações girariam em torno do padrão de divisão das tarefas domésticas, do pouco tempo disponível que as mulheres possuem para deslocamento e influências ainda persistentes da configuração tradicional das famílias norte-americanas (Crane, 2007).

\section{Gráfico 10 - Tempo de deslocamento casa-trabalho segundo sexo e nível de renda - regiões metropolitanas - 1992-1993 e 2012-2013 (em minutos)}

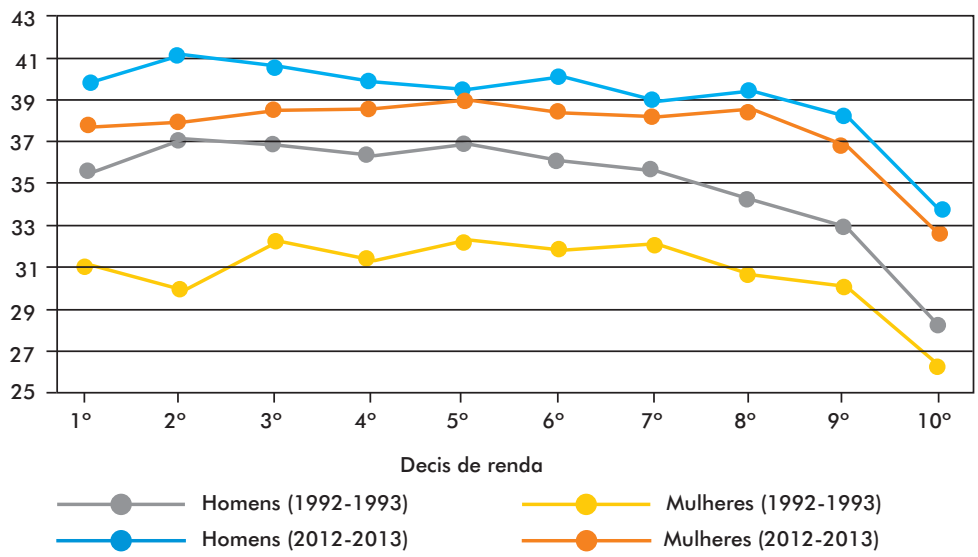

Fonte: PNAD/IBGE.

A tendência geral de diminuição na diferença também se mantém por nível de renda ao longo do tempo, como pode ser observado no Gráfico 10. É possível observar que ambas as curvas se deslocam para cima na passagem ao longo do tempo, porém, a 
distância relativa entre elas diminui consideravelmente, principalmente nos decis centrais da distribuição, havendo, portanto, certa resistência nos extremos da distribuição.

Com relação a esse fenômeno, acredita-se que suas causas fundamentais se originam nos hábitos e comportamentos cotidianos, de acordo com os quais as famílias de diferentes estratos socioeconômicos alocam de forma diferente o tempo de trabalho e das atividades domésticas entre os homens e as mulheres, assim como os efeitos das diferenças de acesso ao transporte individual e de nível de renda (Pereira e Schwanen, 2013).

\subsection{DIFERENÇAS POR COR}

Segundo o Censo 2010, 98,4\% da população brasileira se autodeclara branca, preta ou parda. Uma prática metodológica comum é unificar pretos e pardos em um único grupo populacional. O Gráfico 11 apresenta o tempo de deslocamento para a população autodeclarada branca e a população preta ou parda no conjunto das regiões metropolitanas brasileiras.
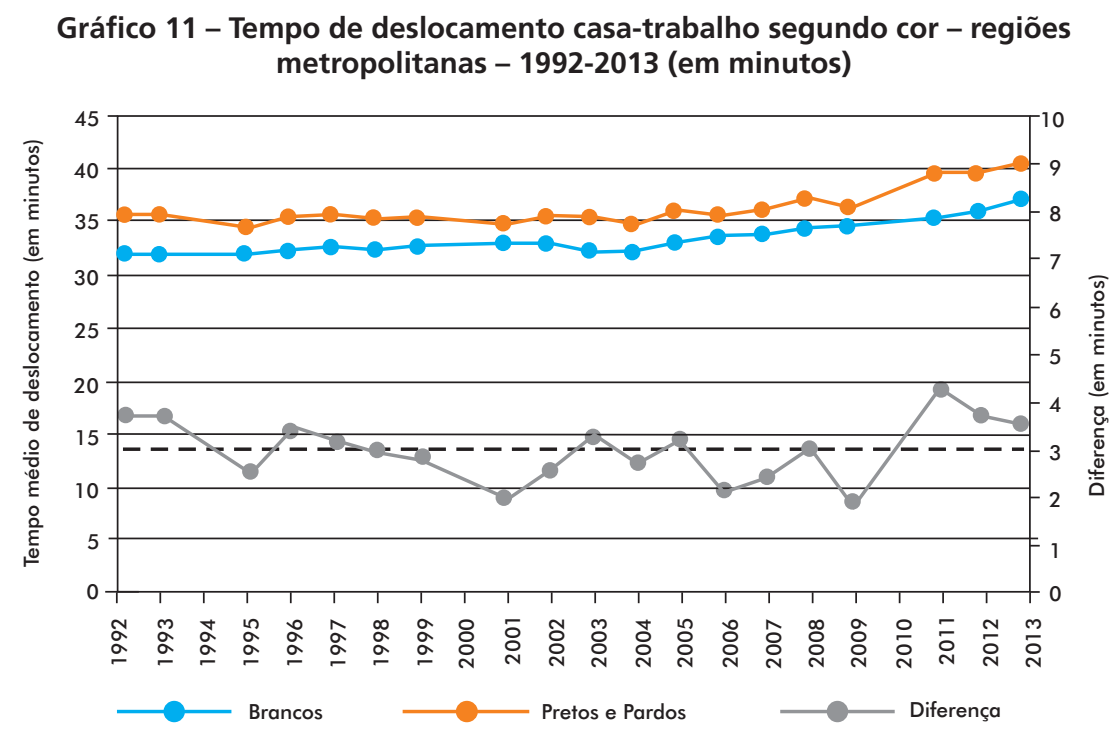

Fonte: PNAD/BGGE.

A primeira constatação é de que pretos e partos levam um tempo de deslocamento casa-trabalho maior do que o registrado entre brancos, e que essa diferença se mantém ao longo de todo o período analisado, de forma aproximadamente constante, variando cerca de três minutos. Embora essa diferença tenha registrado seu valor máximo em 
anos recentes (4,2 minutos em 2011) e, no longo prazo, o tempo médio de deslocamento entre brancos tenha crescido mais (16,5\% contra $14,3 \%$ entre pretos e pardos), não há ainda uma tendência clara.

\section{Gráfico 12 - Tempo de deslocamento casa-trabalho segundo cor e nível de renda - regiões metropolitanas - 1992-2013 (em minutos)}

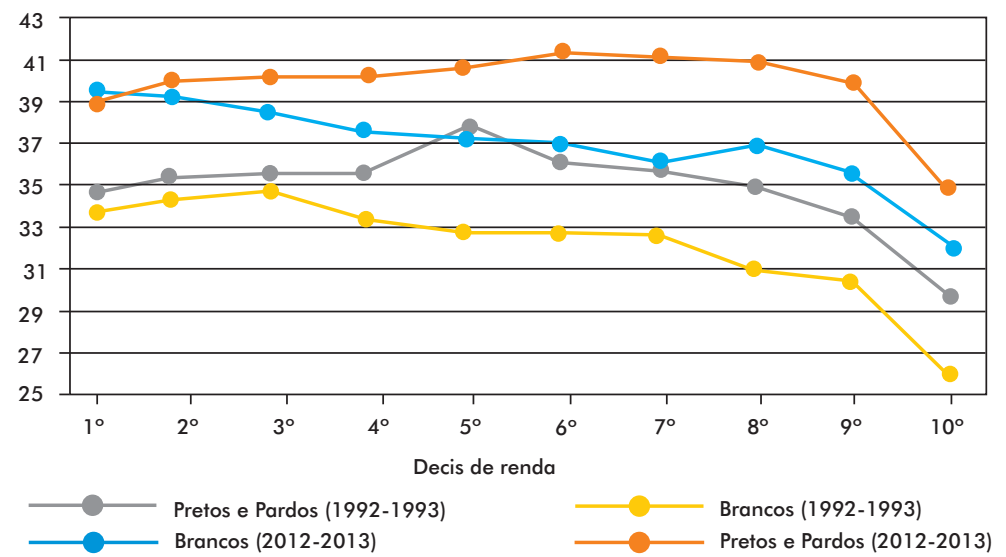

Fonte: PNAD/IBGE.

Com respeito à renda, as mudanças ao longo das últimas duas décadas apresentam desdobramentos ainda mais complexos do que os registrados em relação a gênero. Entre os brancos, o aumento no tempo de deslocamento foi mais sentido nos extremos da distribuição, seguindo uma tendência mais geral observada em praticamente todas as análises. Porém, entre os que se autodeclaram pretos ou pardos, o aumento no tempo de deslocamento foi maior a partir do sexto decil. Comparando os dois grupos entre si ao longo do período, percebe-se que para o primeiro decil de renda, a piora nas condições de transporte atingiu mais os brancos do que as populações negras (pretos e pardos), com emparelhamento nos tempos de deslocamento dos dois grupos nesse decil no biênio mais recente: brancos levavam 39,5 minutos para chegar ao trabalho, contra 39 minutos de pretos e pardos. No decil mais rico, a população de cor branca também tem sofrido mais com congestionamentos: o tempo de deslocamento para esse grupo aumentou em $21,8 \%$ no período, enquanto entre pretos e pardos foi de $17,0 \%$. A diferença do tempo de deslocamento entre os dois grupos registrou maiores aumentos no terceiro e no sexto decis, ou seja, nesses decis a desigualdade entre brancos e negros em termos de tempo de deslocamento elevou-se (em 100\% e 65\%, respectivamente), enquanto as maiores reduções foram vistas nos primeiros dois decis da distribuição (-158\% e -49\%, respectivamente). Assim, o que se observa é uma piora nas condições de transporte dos negros com renda média (terceiro ao sétimo decis). 


\subsection{DIFERENÇAS RELATIVAS AO POSTO DE TRABALHO}

Quando se analisa o tempo de deslocamento de acordo com o tipo de posto de trabalho, observa-se que os trabalhadores formais têm, historicamente, apresentado tempo de deslocamento de casa ao trabalho mais elevado do que aqueles que ocupam um posto de trabalho não formal. Existem claras diferenças de tempo de deslocamento entre os dois grupos, que têm se agravado ao longo do tempo, como sugere a tendência crescente na curva cinza do Gráfico 13, em especial pós-2005. Essa diferença cresce, principalmente, devido à maior elevação no tempo de deslocamento dos trabalhadores formais. Entre 2005 e 2013, o tempo médio de ida ao trabalho aumentou em 13\% entre os trabalhadores com carteira assinada, mas apenas $4 \%$ entre os não formais.

\section{Gráfico 13 - Tempo de deslocamento casa-trabalho segundo posto de trabalho - regiões metropolitanas - 1992-2013 (em minutos)}

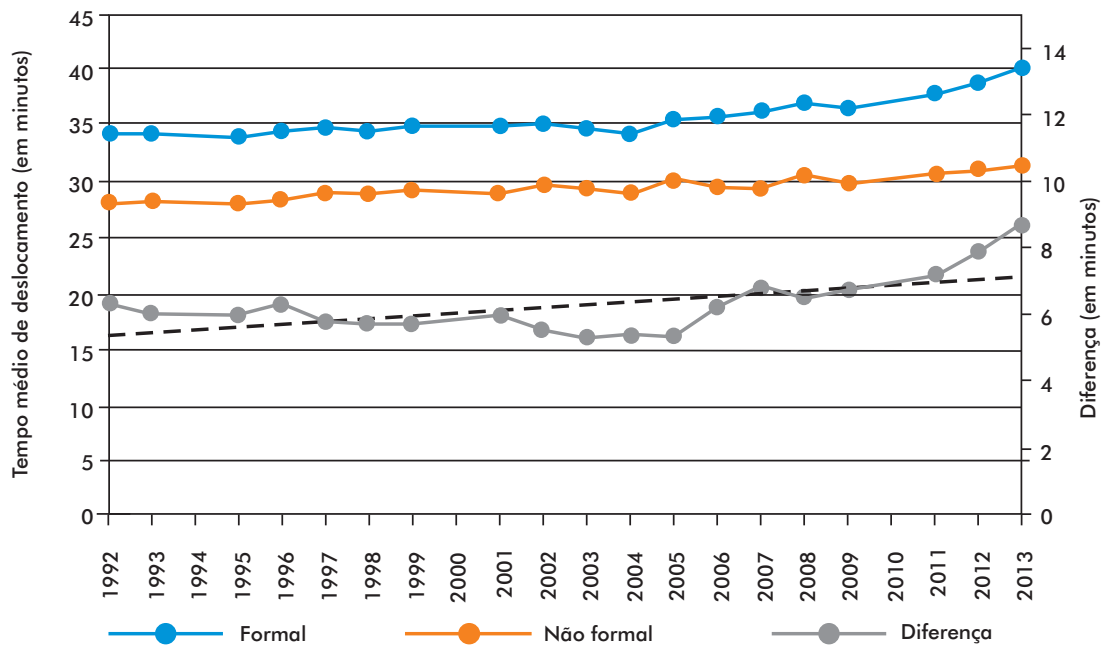

Fonte: PNAD/BGE.

Na relação trabalho e transporte existe uma variável de especial relevância e interesse: o recebimento de algum tipo de auxílio-transporte. O Gráfico 14 apresenta o tempo de deslocamento entre aqueles que recebem o auxílio mensal e aqueles que não o recebem. É nesse critério que se encontra a maior diferença entre todas as características analisadas. Em 2013, aqueles que recebiam o auxílio transporte faziam viagens, aproximadamente, $28 \%$ mais longas do que aqueles que não recebiam.

Em 2013, entre os trabalhadores que recebiam auxílio-transporte, 92\% eram formais e apenas $8 \%$ não formais. Dentre os que não recebiam nenhum tipo de auxílio, 
$71 \%$ eram formais e $29 \%$ não formais. Analisando o grupo dos trabalhadores formais, $70 \%$ recebiam algum tipo de auxílio, enquanto os 30\% restantes não recebiam. Entre os não formais, aproximadamente 33\% recebiam auxílio-transporte e dois terços não contavam com nenhum tipo de ajuda destinada a cobrir os custos de transporte.

\section{Gráfico 14 - Tempo de deslocamento casa-trabalho de acordo com recebimento de auxílio transporte - regiões metropolitanas - 1992-2013 (em minutos)}

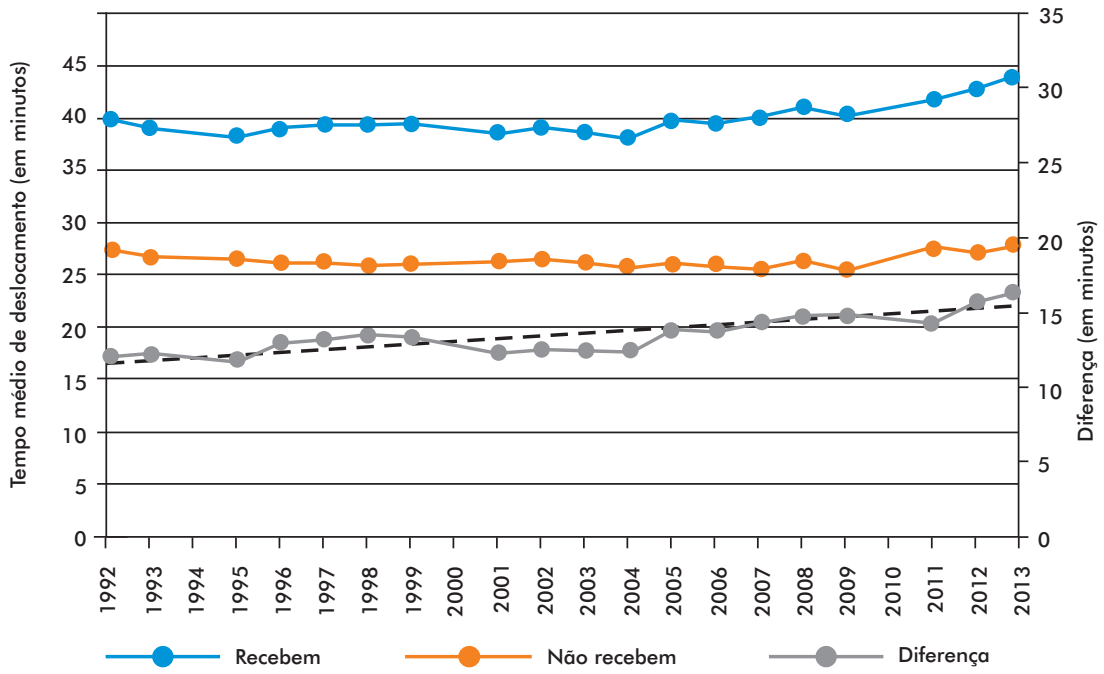

Fonte: PNAD/IBGE.

Subdivide-se a população, então, em quatro grupos: (1) formais que recebem auxílio; (2) não formais que recebem auxílio; (3) formais que não recebem auxílio; e (4) não formais que não recebem auxílio. Dessa forma é possível entender melhor como essas características interferem no tempo de deslocamento casa-trabalho. Para os trabalhadores pertencentes ao grupo 1, o tempo médio de ida ao trabalho, em 2013, foi de 45,1 minutos, o maior registrado entre todos os grupos. O segundo maior tempo foi o dos trabalhadores do grupo 2, que gastam em média 39,6 minutos para ir de casa ao trabalho. O grupo 3 apresentou um tempo de deslocamento de 28,6 minutos, enquanto o último grupo obteve um resultado um pouco menor, 27,5 minutos.

Aparentemente, o recebimento de auxílio-transporte está relacionado com maiores tempos de deslocamento casa-trabalho, embora não se possa afirmar com certeza qual seria o sentido dessa causalidade. Uma hipótese possível seria a de que oportunidades de emprego com auxílio-transporte incluso se tornariam mais atrativas para trabalhadores residentes em localidades distantes. 
O Gráfico 15 apresenta o tempo de deslocamento por renda dos trabalhadores que recebiam e dos que não recebiam auxílio-transporte em dois momentos distintos, 1992-1993, e vinte anos depois, em 2012-2013. Enquanto o grupo que recebia auxílio apresentou o mesmo padrão de aumento visto em análises anteriores, o grupo que não recebia só apresentou aumento nos últimos decis da distribuição, tendo o restante tido seu tempo de ida ao trabalho pouco alterado. Isso sugere que as mudanças estruturais nos sistemas de transporte das regiões metropolitanas ocorridas nas últimas duas décadas afetaram muito pouco esse grupo da população; talvez porque este não utilize os meios de transportes mais suscetíveis a esses efeitos, optando, por exemplo, por ir a pé ou de bicicleta para o trabalho, o que é factível para deslocamentos que levam menos que 30 minutos, ou ainda utilizando meios de transporte mais diretos, como trem e metrô, que não têm integração com o sistema rodoviário.

\section{Gráfico 15 - Tempo de deslocamento casa-trabalho de acordo com recebimento de auxílio transporte e nível de renda - regiões metropolitanas - 1992-1993 e 2012-2013 (em minutos)}

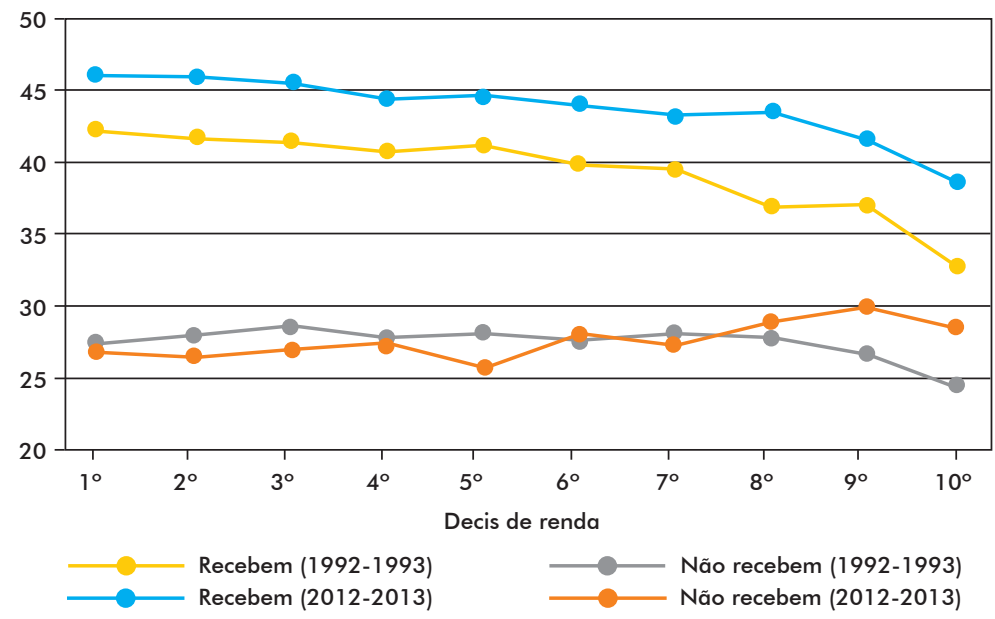

Fonte: PNAD/IBGE

Entretanto, essa explicação não elucida o problema dos decis mais ricos (oitavo ao décimo), nos quais o tempo de deslocamento não só aumentou como se tornou maior do que o de todos os outros decis de renda, o que foge ao comportamento visto em outros recortes para essa ponta da distribuição. $\mathrm{O}$ alto nível de renda, junto ao fato do não recebimento de auxílio-transporte, pode significar que é nesses grupos em que estão concentrados empregadores e "conta-própria" de mais alta renda, o que seria compatível com os resultados apresentados no Gráfico 16, no qual o grupo "Não 
formal"15, no período 2012-2013, mostra o mesmo aumento singular para os últimos três decis da distribuição.

\section{Gráfico 16 - Tempo de deslocamento casa-trabalho segundo posto de trabalho e nível de renda - regiões metropolitanas - 1992-1993 E 2012-2013 (em minutos)}

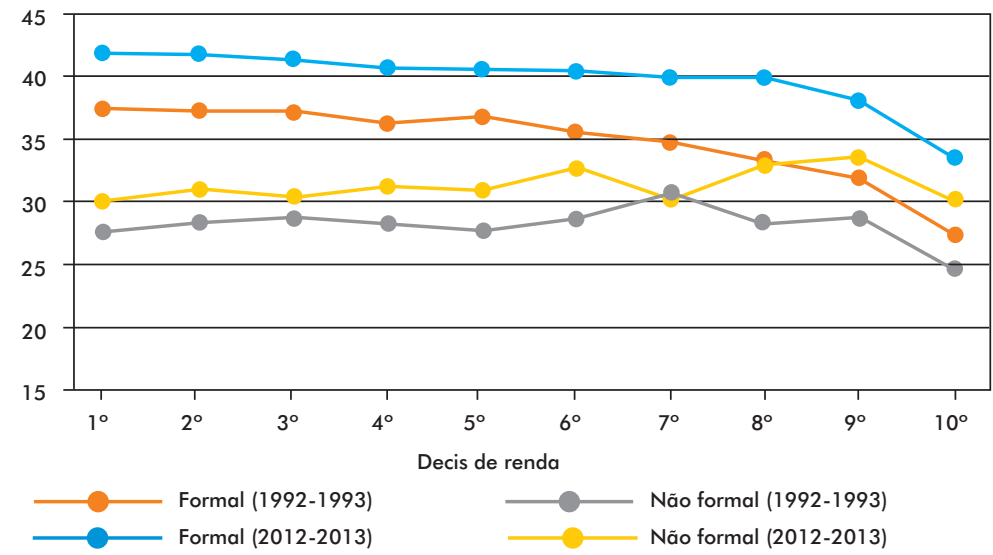

Fonte: PNAD/IBGE.

Tendo em vista o comportamento de diferentes grupos da população ao longo do tempo e alguns resultados intrigantes (como o aumento do tempo de deslocamento dos decis mais ricos da população) fica evidente que a questão da mobilidade urbana, especialmente nas regiões metropolitanas do Brasil, requer investigações muito mais profundas do que as apresentadas no presente estudo. A fim de avançar mais no entendimento dos determinantes do tempo de deslocamento, futuros estudos poderiam levar em consideração: (1) o local de residência e o local de trabalho dos indivíduos (em nível de município e bairro); e (2) o tipo de transporte majoritariamente utilizado nesse trajeto. Porém, essas duas variáveis não estão disponíveis conjuntamente nem na PNAD e nem no Censo (que traz apenas a primeira), de modo que seria necessária uma pesquisa especial com esse fim, o que impõe limitações ao avanço do conhecimento nesse campo.

\footnotetext{
${ }^{15}$ No qual empregadores e "conta-própria" estão alocados.
} 


\section{CONSIDERAÇÕES FINAIS}

O deslocamento de casa até o trabalho tem consumido cada vez mais o tempo e a energia dos trabalhadores das grandes metrópoles do país. A demora para chegar ao trabalho reduz produtividade, gerando um duplo efeito negativo sobre bem-estar, na medida em que este se reduz no nível do indivíduo (via redução do tempo livre e seus efeitos sobre saúde e bem-estar) e para a sociedade como um todo (afetada pelo somatório das perdas de produtividade individuais).

A tendência de elevação do tempo médio de deslocamento casa-trabalho se acentuou no terceiro milênio, principalmente a partir de 2003. Porém, tal movimento não é uniforme, havendo localidades cuja deterioração das condições de transporte tem ocorrido de forma mais acentuada do que em outras. Esse é o caso da RMRJ e da RMSP, que já atingiram tempos médios de deslocamento acima dos 45 minutos e são notoriamente conhecidas por sofrerem com problemas de mobilidade urbana. Ao mesmo tempo, outras regiões metropolitanas, como Pará, Recife e Salvador, têm apresentado um crescimento no tempo médio de deslocamento acima dos registrados na região Sudeste do país, ou seja, tais localidades estão se aproximando de um cenário crítico de forma acelerada, o que coloca em evidência a necessidade de melhor direcionamento e planejamento de políticas públicas na área de mobilidade urbana.

O tempo de deslocamento não apresenta diferenças apenas na comparação entre regiões metropolitanas. Em relação à diferença entre homens e mulheres, as regiões metropolitanas brasileiras seguem o padrão internacional: os tempos médios de deslocamento dos homens se apresentam maiores do que os das mulheres. Essa diferença, no entanto, tem diminuído ao longo do tempo, devido ao aumento do tempo médio de deslocamento das mulheres. Em 2013 praticamente não existe diferença alguma, o que aponta uma tendência diversa do contexto norte-americano, em que há persistência do diferencial entre sexos. Na medida em que o deslocamento, o aumento do tempo de deslocamento é relativamente maior para as mulheres, torna-se evidente a necessidade de uma maior discussão de políticas de mobilidade urbana sensíveis a gênero, que pode ser tanto via maior participação das mulheres na formulação de políticas públicas na área de transportes públicos como pelo lado do desenvolvimento local com oportunidades de trabalho mais próximas ao lar, por exemplo, em atividades empreendedoras, entre outras.

Os resultados empíricos sugerem que o tempo de deslocamento de pretos e pardos é mais elevado do que o dos brancos, no geral. Porém, ao contrário do que se observa na análise comparativa entre sexos, não houve redução da diferença, de modo que, em um primeiro momento, pode-se inferir que cor exerce uma influência significativamente persistente sobre tempo de deslocamento. 
Aqueles que têm um emprego formal, em média, apresentam tempos de deslocamento superiores aos dos trabalhadores informais. De fato, os maiores tempos de deslocamento são para os empregados formais que recebem auxílio-transporte, verificando-se a estabilidade dessa diferença ao longo do tempo. Embora não se possa afirmar a razão dessa causalidade, é possível que represente condições ou oportunidades de emprego mais atrativas para trabalhadores residentes em localidades distantes.

A influência da renda, mesmo quando combinada a outras características, segue uma tendência geral: os mais pobres e os mais ricos (extremos da distribuição de renda) tendem a apresentar tempos de deslocamento menores do que os do restante da população e relativamente próximos. Uma explicação possível seria que o raio de busca por empregos dos mais pobres é menor, ou seja, há limitação na procura por emprego em razão de os custos de transporte serem impeditivos; enquanto, para os mais ricos, há a possibilidade de arcar com os custos de residir mais perto dos polos de emprego e, ao mesmo tempo, utilizar transporte individual motorizado. Dessa forma, os dois grupos registram tempos de deslocamento casa-trabalho baixo. Apesar de mais alto entre os estratos intermediários, o tempo médio de deslocamento aumentou entre os mais pobres, mostrando uma face da exclusão social. Porém, esse aumento foi maior para os mais ricos, colocando a questão da mobilidade urbana para além dos problemas de exclusão social.

Assim, vale ressaltar que há atualmente em curso um processo de deterioração das condições de mobilidade urbana, medido pelo aumento do tempo de deslocamento de casa ao trabalho, com impactos sobre o bem-estar dos trabalhadores, principalmente dos mais vulneráveis. Assim, é imperativo que os formuladores de políticas públicas reorientem suas prioridades no que diz respeito ao meio urbano e iniciem um vasto empreendimento de recuperação dos sistemas de transporte públicos metropolitanos, com foco na modernização, acessibilidade, ampliação, integração e sustentabilidade.

Dentre as medidas que poderiam ser tomadas para equacionar a problemática do tempo de deslocamento nas principais regiões metropolitanas, destacam-se algumas no debate atual: (1) concentrar os esforços de programas habitacionais nas áreas centrais, isto é, mais próximas dos polos de emprego, para famílias de baixa renda; (2) planejar a criação de bolsões de estacionamento fora da área central, com ligação direta com outros modais de alta capacidade, de modo que os trabalhadores possam ir de casa até uma fronteira de acesso, deixar seu carro e seguir viagem por meio de uma integração, a fim de que o tempo ganho com a utilização do modal de alta capacidade mais do que compensasse o tempo gasto na integração; (3) implementar ciclovias ligando toda a extensão da região metropolitana, e não apenas áreas isoladas entre si, com bases instaladas nas estações de transporte público de massa e também com estrutura adequada para tal nos locais de trabalho; e (4) incentivar a flexibilidade de 
horários de trabalho, reavaliando a necessidade da grande maioria dos trabalhadores entrar e sair de seus empregos no mesmo horário, o que sobrecarrega o sistema de transporte no período de rush; e (5) avaliar a necessidade de pagamento no momento do embarque e a viabilidade da tarifa zero, que aceleraria o tempo de viagem, na medida em que reduziria o tempo que os coletivos precisam permanecer parados para embarque e pagamento por parte dos passageiros.

Por fim, abordando a questão da mobilidade urbana nas grandes metrópoles brasileiras sob o ângulo do tempo perdido no deslocamento de casa ao trabalho, as políticas públicas devem ser formuladas de modo a considerar conjuntamente desde melhorias no setor de transporte até medidas para incentivar o desenvolvimento local. Se o objetivo é diminuir o tempo de deslocamento, a expansão e a melhoria dos modais e da malha de transporte público nas metrópoles devem ser planejadas com outras áreas como habitação e trabalho, considerando a participação e a demanda da população para o desenvolvimento local.

\section{REFERÊNCIAS}

ALONSO, W. Location and land use. Cambridge: Harvard University Press, 1964.

BRANCO, A. M. Os custos sociais do transporte urbano brasileiro. Revista dos Transportes Públicos, ANTP, São Paulo, n. 84, 1999.

BLACK, D.; KOLESNIKOVA, N.; TAYLOR, L. J. Why do so few women work in New York (and so many in Minneapolis)? Labor supply of married women across US Cities. Federal Reserve Bank of St. Louis Working Paper, n. 2007-043D, 2008. Disponível em: <http://ssrn.com/ abstract=1129982>. Acesso em: 17 jul. 2014.

CERVERO, R.; WU, K. L. Sub-centering and commuting: evidence from the San Francisco Bay Area. Urban Studies, v. 35, p. 1059-1076, 1998.

CHURCH, A.; FROST, M. AND SULLIVAN, K. Transport and social Exclusion in London. Transport Policy, v. 7, p. 195-205, 2000.

CINTRA, M. Os custos dos congestionamentos na capital paulista. Conjuntura Econômica, jun. 2008. Disponível em: <http://www.marcoscintra.org>. Acesso em: 22 jul. 2014.

CRANE, R. Is there a quiet revolution in women's travel? Revisiting the gender gap in commuting. Journal of the American Planning Association, v. 3, n. 7, p. 298-316, 2007.

CRANE, R.; TAKAHASI, L. Sex changes everything: the recent narrowing and widening of travel differences by gender. Public Works Management \& Policy, v. 4, n. 13, p. 328-337, 2009.

FIRJAN. Os custos da (i)mobilidade nas regiões metropolitanas do Rio de Janeiro e São Paulo. Nota Técnica, n. 3, jul. 2014.

GIBBONS, S.; MACHIN, S. Transport and labour market linkages: empirical evidence, implications for policy and scope for further UK Research. Londres: The Eddington Study, dez. 2006. 
GIN, A.; SONSTELIE, J. The streetcar and residential location in 19th century Philadelphia. Journal of Urban Economics, v. 32, pp. 92-107, 1992.

GLAESER. L. E. Are cities dying? The Journal of Economic Perspectives, v. 12, n. 2, 1998.

IBGE - INSTITUTO BRASILEIRO DE GEOGRAFIA E ESTATISTICA. Pesquisa Nacional por Amostra de Domicílios - PNAD 1992 a 2013. Rio de Janeiro: IBGE, 1992.

INSTITUTO AKATU. “O que move nosso País?”. Valor Econômico, 17 mar. 2014. Disponível em: <http://www.akatu.org.br/Temas/Mobilidade/Posts/O-que-move-nosso-Pais>. Acesso em: 22 de jul. 2014

LAGO, L. C.; MAMMARELLA, R. Da hierarquia de classes à organização social do espaço intraurbano: um olhar comparativo sobre as grandes metrópoles brasileiras. Cadernos Metrópole, v. 12, p. 65-84, 2010. Disponível em: <http://migre.me/8BNVL>. Acesso em: 22 de jul. 2014

LEITÃO, S. R. Inclusão do Excluído? Política de mobilidade e dinâmica do mercado de terras na expansão da Curitiba Metrópole. Dissertação de Mestrado, Pós-graduação em Estruturas Ambientais Urbanas, Faculdade de Arquitetura e Urbanismo, Universidade de São Paulo, São Paulo, 2010.

LEVINSON, D. M.; KUMAR, A. The rational locator: why travel times have remained stable. Journal of the American Planning Association, v. 60, p. 319-332, 1994.

LEVINSON, D.; WU, Y. The rational locator re-examined. Transportation, v. 32, p. 187-202, 2005.

LEVITAS, R. et al. The multidimensional analysis of social exclusion. Bristol, UK: Department of Sociology and School for Social Policy, Townsend Centre for the International Study of Poverty and Bristol Institute for Public Affairs, University of Bristol, 2007.

LUCAS, K. Transport and social exclusion: where are we now? Transport Policy, v. 20, p. 105$113,2012$.

MAGAGNIN, R. C.; SILVA, A. N. R. A percepção do especialista sobre o tema mobilidade urbana. Revista Transportes, v. 16, n. 1, p. 25-35, jun. 2008.

MARTINE, G.; OJIMA, R.; FIORAVANTE, E. F. “Transporte individual, dinâmica demográfica e meio ambiente”. In: MARTINE, R. G. et al. População e sustentabilidade na era das mudanças ambientais globais. Campinas: ABEP, 2012, p. 175-185.

MCLAFFERT, S.; PRESTON, V. Spatial mismatch and employment in a decade of restructuring. The Professional Geographer, n. 48, v. 4, pp. 420-431, 1996.

MIHESSEN, V. Mobilidade urbana e mercado de trabalho no Rio de Janeiro metropolitano. Dissertação de Mestrado, Pós-graduação em Ciências Econômicas, Centro de Ciências Sociais Aplicadas, Universidade Federal Fluminense, Niterói, 2014.

MIHESSEN, V.; PERO, V. Mobilidade urbana e pobreza no Rio de Janeiro. In: ENCONTRO NACIONAL DA ABET, 13, Curitiba, 2013.

MORAES, A. C. Congestionamento urbano: custos sociais. Revista ANTP, São Paulo, n. 135, p. 41-48, 2013.

MUTH, R. F. Cities and housing. Chicago: University of Chicago Press, 1969.

PEREIRA, R. H. M.; SCHWANEN, T. Tempo de deslocamento casa-trabalho no Brasil: (19922009): diferenças entre regiões metropolitanas, níveis de renda e sexo. Texto para Discussão, IPEA, n. 1813, 2013. 
PERO, V.; MIHESSEN, V.; MACHADO, D. C. Mobilidade urbana e mercado de trabalho na Região Metropolitana do Rio de Janeiro. Observatório SEBRAE, Estudo Estratégico, Rio de Janeiro, n. 6, set. 2013.

OJIMA, R.; MARANDOLA Jr., E. Mobilidade populacional e um novo significado para as cidades: dispersão urbana e reflexiva na dinâmica regional não metropolitana. Revista Brasileira de Estudos Urbanos e Regionais, ANPUR, Rio de Janeiro, v. 14, n. 2, 2012.

OJIMA, R.; MONTEIRO, F. F.; NASCIMENTO, T. C. L. Deslocamentos pendulares, reestruturação produtiva e o consumo do espaço na urbanização brasileira: explorando o tempo de deslocamento casa-trabalho. In: SIMPÓSIO NACIONAL DE GEOGRAFIA URBANA, 13, Rio de Janeiro, nov. 2013.

RIBEIRO, L. C. Q.; RODRIGUES, J. M.; CORRÊA, F. S. Segregação residencial e emprego nos grandes espaços urbanos brasileiros. Cadernos Metrópole, v. 12, p. 15-41, 2010.

RIVIÈRE D'ARC, H. Pode-se falar, nestes anos 2000, de um modelo latino-americano de cidade ou metrópole? Ponto de vista de uma europeia. Caderno Metrópole, São Paulo, v. 16, n. 31, p. 139-147, jun. 2014.

VAN OMMEREN, J. N.; GUTIÉRREZ, E. Labour supply and commuting. Journal of Urban Economics, v. 68, p. 82-89, 2010.

VAN OMMEREN, J. N.; RIETVELD, P. The commuting time paradox. Journal of Urban Economics, v. 58, n. 3, p. 437-454, 2005.

VAN OMMEREN, J.; VAN DEN BERG, G. J.; GORTER, C. Estimating the marginal willingness to pay for commuting. Journal of Regional Science, v. 40, p. 541-563, 2000.

VASCONCELLOS, E. A.; CARVALHO, C. H.; PEREIRA, R. H. Transporte e mobilidade urbana. Textos para Discussão CEPAL-IPEA, n. 34, 2011.

YOUNG, C. E. F.; AGUIAR, C. F. Sinal fechado: o custo econômico do tempo de deslocamento para o trabalho na Região Metropolitana do Rio de Janeiro. In: ENCONTRO DA SOCIEDADE BRASILEIRA DE ECONOMIA ECOLÓGICA, 5, Vitória, set. 2013. Anais... 2013, p. $17-21$. 